NBER WORKING PAPER SERIES

\title{
SUDDEN STOPS, FINANCIAL CRISES AND LEVERAGE: A FISHERIAN DEFLATION OF TOBIN'S Q
}

\author{
Enrique G. Mendoza \\ Working Paper 14444 \\ http://www.nber.org/papers/w14444 \\ NATIONAL BUREAU OF ECONOMIC RESEARCH \\ 1050 Massachusetts Avenue \\ Cambridge, MA 02138 \\ October 2008
}

I am grateful to Guillermo Calvo, Dave Cook, Mick Devereux, Gita Gopinath, Tim Kehoe, Nobuhiro Kiyotaki, Narayana Kocherlakota, Juan Pablo Nicolini, Marcelo Oviedo, Helene Rey, Vincenzo Quadrini, Alvaro Riascos, Lars Svensson, Linda Tesar and Martin Uribe for helpful comments. I also acknowledge comments by participants at the 2006 Texas Monetary Conference, 2005 Meeting of the Society for Economic Dynamics, the Fall 2004 IFM Program Meeting of the NBER, and seminars at the ECB, BIS, Bank of Portugal, Cornell, Duke, Georgetown, IDB, IMF, Harvard, Hong Kong Institute for Monetary Research, Hong Kong University of Science and Technology, Johns Hopkins, Michigan, Oregon, Princeton, UCLA, USC, Western Ontario and Yale. Many thanks also to Guillermo Calvo, Alejandro Izquierdo, Rudy Loo-Kung and Ernesto Talvi for allowing me to use their classification of Sudden Stop events. The views expressed herein are those of the author(s) and do not necessarily reflect the views of the National Bureau of Economic Research.

NBER working papers are circulated for discussion and comment purposes. They have not been peerreviewed or been subject to the review by the NBER Board of Directors that accompanies official NBER publications.

(C) 2008 by Enrique G. Mendoza. All rights reserved. Short sections of text, not to exceed two paragraphs, may be quoted without explicit permission provided that full credit, including $@$ notice, is given to the source. 
Sudden Stops, Financial Crises and Leverage: A Fisherian Deflation of Tobin's Q

Enrique G. Mendoza

NBER Working Paper No. 14444

October 2008

JEL No. D52,E32,E44,F32,F41

\begin{abstract}
$\underline{\text { ABSTRACT }}$
This paper shows that the quantitative predictions of a DSGE model with an endogenous collateral constraint are consistent with key features of the emerging markets' Sudden Stops. Business cycle dynamics produce periods of expansion during which the ratio of debt to asset values raises enough to trigger the constraint. This sets in motion a deflation of Tobin's Q driven by Irving Fisher's debt-deflation mechanism, which causes a spiraling decline in credit access and in the price and quantity of collateral assets. Output and factor allocations decline because the collateral constraint limits access to working capital financing. This credit constraint induces significant amplification and asymmetry in the responses of macro-aggregates to shocks. Because of precautionary saving, Sudden Stops are low probability events nested within normal cycles in the long run.
\end{abstract}

\author{
Enrique G. Mendoza \\ Department of Economics \\ University of Maryland \\ College Park, MD 20742 \\ and NBER \\ mendozae@econ.umd.edu
}


"A story is a string of actions occurring over time, and debt happens as a result of actions occurring over time. Therefore, any debt involves a plot line: how you got into debt, what you did, said and thought while you were there, and then-depending on whether the ending is to be happy or sad-how you got out of debt, or else how you go further and further into it until you became overwhelmed by it, and sank from view." (Margaret Atwood, "Debtor's Prism," Wall Street Journal, 09/20/2008, p. W1)

\section{Introduction}

The Great Depression showed that market economies can experience deep recessions that differ markedly from typical business cycle downturns. The recessions that hit emerging economies in the aftermath of the financial crises of the late 1990s illustrated the same fact. In contrast with the Great Depression, however, the loss of access to world capital markets played a key role in emerging markets crises. That is, these crises featured the phenomenon now commonly referred to as a "Sudden Stop."

Three striking macroeconomic regularities characterize Sudden Stops: (1) reversals of international capital flows, reflected in sudden increases in net exports and the current account, (2) declines in domestic production and absorption, and (3) corrections in asset prices. Figure 1 illustrates these facts using five-year event windows, centered on Sudden Stop events occurring at date $t$. The dating and location of Sudden Stops follows Calvo, Izquierdo and Talvi's (2006) classification. ${ }^{1}$ The charts show event dynamics for output $(G D P)$, consumption $(C)$, investment $(I)$, the net exports-GDP ratio $(N X Y)$ and Tobin's $Q$. Data for $G D P, C, I$, and $N X Y$ are from World Development Indicators. $Q$ is estimated for each country as the median across firm-level estimates computed for listed corporations using Worldscope data. Firm-level $Q$ is the ratio of market value of equity plus debt outstanding to book value of equity. The observations in the event windows correspond to cross-country medians of deviations from Hodrick-Prescott trends estimated using 1970-2006 data for each country, except for $Q$ which is not detrended because the data starts in $1994 .^{2}$

As Figure 1 shows, Sudden Stops are preceded by expansions, with domestic absorption and production above trend, the trade balance below trend, and high asset prices. The median Sudden Stop displays a reversal in the cyclical component of $N X Y$ of about 3 percentage points of GDP, from a deficit of about 2 percent of GDP at $t-1$ to a surplus of 1 percent of GDP at $t$, and this surplus persists at $t+1$ and $t+2$. GDP and $C$ are about 4 percentage points below trend at date $t$, and $I$ collapses almost 20 percentage points below trend. The economies recover somewhat afterwards, but GDP, $C$ and $I$ remain below trend two years after the Sudden Stops hit. $Q$ reaches a through at date $t$ about 13 percentage points below the pre-Sudden-Stop peak, and it recovers about $2 / 3$ rds of its value by $t+2$.

${ }^{1}$ Calvo et al. identified 33 Sudden Stop events with large and mild output collapses in a sample including the 31 countries that JP Morgan defines as emerging markets. Their paper provides further details. Calvo and Reinhart (1999), Calvo, Izquierdo and Loo-Kung (2006), and Milesi-Ferretti and Razin (2000) use other definitions of Sudden Stops, but the actual listings of events are very similar.

${ }^{2}$ Note two differences with the event analysis in Calvo et al. First, they study event windows with cross-country averages of country-specific cumulative growth rates. We use medians instead of averages because of substantial cross-country dispersion in cyclical components, and deviations from trend instead of cumulative growth to remove low-frequency dynamics. Second, Calvo et al. focus mainly on Sudden Stops with large output collapses. Here we include all Sudden Stop events. 
In addition to the stylized facts illustrated in Figure 1, Sudden Stops are characterized by three important features: First, Sudden Stops are nested within typical business cycles. They are rare events in each country by construction, because a key criterion to identify them is that a country's international capital flows are significantly below their mean (see Calvo et al. (2006)). Second, they represent business cycle asymmetries (i.e., symmetric episodes of sudden large drops in trade surpluses accompanied by surges in output and absorption are not observed). Third, standard growth accounting shows that a large drop in the Solow residual accounts for a Sudden Stops' initial output collapse. Part of this is due to factors that bias the Solow residual as a measure of "true" total factor productivity (TFP), such as changes in imported inputs, capacity utilization, and labor hoarding (see Bergoeing et. al. (2002), Mendoza (2006), and Meza and Quintin (2006)). For instance, Mendoza shows that in Mexico's 1995 Sudden Stop, a large drop in imported inputs accounts for 3.1 percentage points of the 8.5 percent fall in output per worker between the 94:Q3 and 95:Q2.

The characteristics that define Sudden Stops suggest that a dynamic stochastic general equilibrium (DSGE) model aiming to explain this phenomenon should support a stochastic steady state in which infrequent Sudden Stops are nested together with normal business cycles. In addition, the model should display amplification and asymmetry of economic fluctuations during Sudden Stop episodes: Typical realizations of the same underlying exogenous shocks that produce normal business cycles in non-Sudden Stop states should result in reversals of capital flows, economic recessions and declines in asset prices during Sudden Stops. Moreover, Sudden Stops should feature endogenous declines in variables that affect Solow residuals, and these should play a role in the output drop. This paper proposes a model with these properties, and shows that it can deliver quantitative predictions consistent with actual Sudden Stops.

Explaining Sudden Stops is a challenge for a large class of DSGE small open economy (SOE) models, including frictionless real business cycle models and models with nominal rigidities. This is because these models typically assume perfect world credit markets that act as an efficient vehicle for consumption smoothing and investment financing. For example, in response to a large output drop, households formulate optimal plans to smooth the effect on consumption by borrowing from abroad, while in the data the opposite is observed (the external accounts rise sharply precisely when consumption and output collapse). In contrast, the literature on Sudden Stops emphasizes the role of credit frictions. Several studies propose models that predict adjustments in production, absorption and the external accounts as a result of the adverse effects of these frictions (e.g. Auenhaimer and Garcia (2000), Izquierdo (2000), Calvo (1998), Gopinath (2003), Cook and Choi (2003), Cook and Devereux (2006a, 2006b), Martin and Rey (2006), and Gertler, Gilchrist and Natalucci (2007)). The model proposed in this paper follows on a similar path, but it differs in its focus on the amplification and asymmetry of macroeconomic fluctuations that Irving Fisher's (1933) classic debt-deflation transmission mechanism produces.

The model introduces an endogenous collateral constraint with the debt-deflation mechanism into a DSGE-SOE model driven by three standard exogenous shocks affecting TFP, the foreign interest rate, and the price of imported intermediate goods. The collateral constraint limits total debt, including both standard intertemporal debt and atemporal working capital loans, not to exceed a fraction of the market value of the physical capital that serves as collateral. Thus, the constraint imposes an upper bound on the aggregate 
leverage ratio of the economy. The emphasis is on studying the quantitative significance of this credit friction, along the lines of the growing literature on the macroeconomic implications of credit constraints (as in Kiyotaki and Moore (1997), Bernanke, Gertler and Gilchrist (1998), Aiyagari and Gertler (1999), Kocherlakota (2000), Cooley, Miramon and Quadrini (2004), Jermann and Quadrini (2005), and Gertler, et al. (2007)).

Standard DSGE-SOE models cannot produce Sudden Stops even if working capital and/or imported inputs are added. Agents in these models still have unrestricted access to a perfect international credit market. Negative shocks to TFP and/or the world price of imported inputs induce standard consumption-smoothing and investment-reducing effects. Large shocks could trigger large output collapses driven in part by cuts in imported inputs, but this would still fail to explain the current account reversal and the collapse in consumption (since households would borrow from abroad to smooth consumption). Adding large shocks to the world interest rate or access to external financing can alter these results, but such a theory of Sudden Stops would hinge entirely on unexplained "large and unexpected" shocks. Large, because by definition they need to induce recessions larger than the normal non-Sudden-Stop recessions, and unexpected (i.e. outside the set realizations agents consider possible), because otherwise agents would self-insure to undo their real effects. Paradoxically, large, unexpected shocks often drive reversals of capital flows in the models proposed in the Sudden Stops literature (e.g. Calvo (1988)). In contrast, this paper shows that a debt-deflation-style collateral constraint can provide an explanation for Sudden Stops that does not hinge on large, unexpected shocks.

The debt-deflation collateral constraint adds three important elements to the model's business cycle transmission mechanism that are crucial for the quantitative results:

(1) The constraint is occasionally binding, because it only binds when the leverage ratio is sufficiently high. When this happens, the economy responds to typical realizations of the exogenous shocks by displaying Sudden Stops. Moreover, if the constraint does not bind, the shocks yield similar macroeconomic responses as in a typical DSGE-SOE model with working capital and perfect credit markets. As a result, the economy displays "normal" business cycle patterns when the collateral constraint does not bind.

(2) The loss of credit market access is endogenous. In particular, the high leverage ratios at which the collateral constraint binds are reached after sequences of realizations of the exogenous shocks lead the endogenous business cycle dynamics of the economy to states with sufficiently high leverage. Since net exports are countercyclical in the model, these highleverage states are preceded by economic expansions, as observed in emerging economies. However, Sudden Stops have a low long-run probability of occurring, because agents accumulate precautionary savings to reduce the likelihood of large consumption drops. Hence, Sudden Stops are rare events nested within typical business cycles.

(3) Sudden Stops are driven by two "credit channel" effects that induce amplification, asymmetry and persistence in the effects of exogenous shocks. The first is an endogenous financing premium that affects one-period debt, working capital loans, and the return on equity because the effective cost of borrowing rises when the collateral constraint binds. The second is the debt-deflation mechanism: When the collateral constraint binds, agents liquidate capital in order to meet "margin calls." This fire-sale of assets reduces the price of 
capital and tightens further the constraint, setting off a spiraling collapse of asset prices. Consumption, investment and the trade deficit suffer contemporaneous reversals as a result, and future capital, output, and factor allocations fall in response to the initial investment decline. In addition, the restricted access to working capital induces contemporaneous declines in production and factor demands.

The quantitative analysis of the model is conducted using a baseline calibration based on a detailed analysis of Mexican data, but the focus is on exploring the model's ability to match the Sudden Stop features observed across countries. The upper bound on leverage is calibrated so that the model's stochastic stationary equilibrium matches the observed frequency of Sudden Stops in the dataset of Calvo et al. (2006), which is about 3.3 percent. The long-run probability of observing Sudden Stops is reduced by precautionary savings, and hence the model requires an upper bound on the leverage ratio of about $1 / 5$ in order to match the 3.3 percent Sudden Stops probability.

The results show that model economies with and without the collateral constraint exhibit largely the same long-run business cycle co-movements, but the economy with the collateral constraint displays significant amplification and asymmetry in the responses of macroeconomic aggregates to one-standard-deviation shocks. Amplification is reflected in significantly larger average responses conditional on positive-probability states in which the collateral constraint binds. Asymmetry is shown in that the responses to shocks of the same magnitude, but conditional on states in which the collateral constraint does not bind, are about the same in the economies with and without the credit friction.

The ability of the model to replicate observed Sudden Stops is evaluated by conducting stochastic simulations and constructing event analysis windows with the simulated data that are comparable with those shown in Figure 1. The results indicate that the model matches the behavior of output, consumption, investment and net exports, including the collapse when Sudden Stops hit, the periods of economic expansion that precede them, and the pattern of the recovery that follows. The model also replicates the observed dynamics of Tobin's Q qualitatively, but quantitatively it underestimates the collapse of asset prices. Moreover, in the model's Sudden Stop events, the Solow residual overestimates the true estate of TFP by about 30 percent.

Sensitivity analysis shows that the loss of access to working capital financing plays a key role in the model's ability to produce amplification and asymmetry in the responses of GDP and factor allocations, in yielding Sudden Stop dynamics consistent with those observed in the data, and in producing a gap between true TFP and the Solow residual. Increasing the share of imported inputs in production increases the amplitude of the Sudden Stop-induced fluctuations in GDP, factor allocations and working capital, and it also increases the bias between the Solow residual and true TFP (with the former overstating the latter by about 50 percent). The opposite results are obtained if instead of increasing the share of imported inputs in production we lower the Frisch elasticity of labor supply.

The collateral constraint used in this paper is similar to the margin constraint used by Mendoza and Smith (2006) in their extension of the Aiyagari-Gertler (1999) setup to an environment of global asset trading. The model studied here is significantly different, because it is a full-blown equilibrium business cycle model with endogenous capital 
accumulation and dividend payments that vary in response to the collateral constraint, and the constraint limits access to working capital financing. In contrast, Mendoza and Smith study a setup in which production and dividend payments are unaffected by the credit constraint, abstract from modeling capital accumulation, and consider a credit constraint that limits only the access to household debt.

This paper is also closely related to two important strands of the literature that study the quantitative implications of financial constraints for emerging markets business cycles. One is the strand that studies the effects of working capital financing on long-run business cycle co-movements (see Neumeyer and Perri (2005), Uribe and Yue (2006) and Oviedo (2004)). The model of this paper differs in one key respect: Working capital loans require collateral, so that when the collateral constraint binds, the cutoff in working capital loans contributes to the amplification and asymmetry observed in the Sudden Stop responses of output and factor demands to shocks. Moreover, the model is parameterized so that only a small fraction of factor costs needs to be paid in advance. As result, in the absence of the collateral constraint, working capital makes little difference for business cycle dynamics (relative to a frictionless economy).

The second strand of the quantitative business cycles literature related to this paper is the one that introduced the Bernanke-Gertler financial accelerator into DSGE-SOE models with nominal rigidities. Notably, Gertler et al. (2007) calibrated a model of this class to Korean data, and studied its ability to account for the 1997-1998 Korean crash as a response to a large exogenous shock to the real foreign interest rate. In addition, Gertler et al. introduced a mechanism to drive the output collapse together with a decline in productivity as measured by the Solow residual by modeling variable capital utilization. This paper introduces a different financial accelerator mechanism, based on an occasionally binding collateral constraint, and uses imported intermediate goods to produce a decline in the Solow residual. ${ }^{3}$ The qualitative interpretation of the feedback between asset prices and debt is similar to the one in Gertler et al., but the debt-deflation mechanism yields endogenous Sudden Stops that do not require large, unexpected shocks, co-exist with regular business cycles, and produce asymmetric effects that amplify business cycle downturns. On the other hand, since solving the model requires non-linear global solution methods for DSGE-SOE models with incomplete markets, the model is much less flexible than the framework of Gertler et al. for studying the interaction of the financial accelerator with nominal rigidities and monetary and exchange rate policy.

The paper is organized as follows. Section 2 describes the model and characterizes its competitive equilibrium. Sections 3 and 4 focus on calibrating the model and conducting the quantitative analysis. Section 5 concludes.

\section{A Model of Sudden Stops and Business Cycles with Collateral Constraints}

The model economy is a variation of the standard DSGE-SOE model with incomplete insurance markets, capital adjustment costs, and working capital financing (e.g. Mendoza (1991), Neumeyer and Perri (2005) and Uribe and Yue (2006)). Two important

${ }^{3}$ A previous version of this paper used both imported inputs and variable utilization (see Mendoza (2006)). The latter was harder to calibrate and its contribution was quantitatively smaller. 
modifications are introduced here. First, we introduce an endogenous collateral constraint. Second, the supply-side of the model is modified to introduce imported inputs.

\subsection{Optimization problem}

The economy is inhabited by an infinitely-lived, self-employed representative firmhousehold. ${ }^{4}$ The preferences of this agent are defined over stochastic sequences of consumption $c_{t}$ and labor supply $L_{t}$, for $t=0, \ldots, \infty$. Preferences are modeled using Epstein's (1983) Stationary Cardinal Utility (SCU) function, which features an endogenous rate of time preference, so as to obtain a unique, invariant limiting distribution of foreign assets. ${ }^{5}$

The preference specification is:

$$
E_{0}\left[\sum_{t=0}^{\infty} \exp \left\{-\sum_{\tau=0}^{t-1} \rho\left(c_{\tau}-N\left(L_{\tau}\right)\right)\right\} u\left(c_{t}-N\left(L_{t}\right)\right)\right]
$$

In this expression, $u($.$) is a standard twice-continuously-differentiable and concave period$ utility function and $\rho$ (.) is an increasing, concave and twice-continuously-differentiable time preference function. Following Greenwood et al. (1988), utility is defined in terms of the excess of consumption relative to the disutility of labor, with the latter given by the twicecontinuously-differentiable, convex function $N($.). This assumption eliminates the wealth effect on labor supply by making the marginal rate of substitution between consumption and labor independent of consumption.

There are other approaches in addition to using Epstein's SCU that yield well-defined stochastic stationary equilibria in DSGE-SOE models (see Arellano and Mendoza (2003) and Schmitt-Grohe and Uribe (2002) for details). ${ }^{6}$ In models with credit constraints, SCU has the advantage that it can support stationary equilibria in which the constraints can bind permanently. This is because a binding credit constraint drives a wedge between the intertemporal marginal rate of substitution in consumption and the rate of interest. In a stationary state with a binding credit constraint, the rate of time preference adjusts endogenously to accommodate this wedge. In contrast, in models with an exogenous discount factor, credit constraints never bind in the long run (if the rate of time preference is greater

\footnotetext{
${ }^{4}$ Mendoza (2006) presents a different decentralization of a similar setup where firms and households are modeled as separate agents, and face separate collateral constraints. The setup with a selfemployed representative firm-household yields very similar predictions and is much simpler to describe and solve (I am grateful to an anonymous referee for suggesting this approach).

${ }^{5}$ Since agents face non-insurable income shocks and the interest rate is exogenous, precautionary saving leads foreign assets to diverge to infinity with the standard assumption of a constant rate of time preference equal to the interest rate.

${ }^{6}$ Epstein showed that SCU requires weaker preference axioms than those behind the standard utility function with exogenous discounting. Standard preferences require preferences over stochastic future allocations to be risk-independent from past allocations, and past allocations to be risk-independent from future allocations, while SCU only requires the latter. He also proved that a preference order consistent with the weaker axioms can be expressed as a time-recursive utility function if and only if it takes the form of the SCU. Hence, other ad-hoc formulations of endogenous discounting can deliver stationary net foreign asset positions, but they violate the preference axioms.
} 
or equal to the world interest rate) or always bind at steady state (if the rate of time preference is fixed below the interest rate).

The economy operates a constant-returns-to-scale technology, $\exp \left(\varepsilon_{t}^{A}\right) F\left(k_{t}, L_{t}, v_{t}\right)$, that requires capital, $k_{t}$, labor and imported inputs $v_{t}$, to produce a tradable good sold at a worlddetermined price (normalized to unity without loss of generality). TFP is subject to a random shock $\varepsilon_{t}^{A}$ with exponential support. Net investment, $z_{t}=k_{t+1}-k_{t}$, incurs unitary investment costs determined by the function $\Psi\left(z_{t} / k_{t}\right)$, which is linearly homogeneous in $z_{t}$ and $k_{t} \cdot{ }^{7}$ Working capital loans from foreign lenders are needed to pay for a fraction $\phi$ of the cost of imported inputs and labor in advance of sales. The gross interest rate on these loans is the world real interest rate $R_{t}=\operatorname{Rexp}\left(\varepsilon_{t}^{R}\right)$, where $\varepsilon_{t}^{R}$ is an interest rate shock around a mean value $R$. As in Neumeyer and Perri (2005) and Uribe and Yue (2006), working capital loans are provided at the beginning of each period and repaid at the end. Imported inputs are purchased at an exogenous relative price in terms of the world's numeraire $p_{t}=p \exp \left(\varepsilon_{t}^{P}\right)$, where $p$ is the mean price and $\varepsilon_{t}^{P}$ is a shock to the world price of imported inputs (i.e., a terms-of-trade shock from the perspective of the SOE). The shocks $\varepsilon_{t}^{A}, \varepsilon_{t}^{R}$ and $\varepsilon_{t}^{P}$ follow a joint first-order Markov process to be specified in more detail later.

The representative agent chooses sequences of consumption, labor, investment, and holdings of real, one-period international bonds, $b_{t+1}$, so as to maximize SCU subject to the following period budget constraint:

$$
c_{t}+i_{t}+p_{t} v_{t}=\exp \left(\varepsilon_{t}^{A}\right) F\left(k_{t}, L_{t}, v_{t}\right)-\phi\left(R_{t}-1\right)\left(w_{t} L_{t}+p_{t} v_{t}\right)-q_{t}^{b} b_{t+1}+b_{t}
$$

where $i_{t}=\delta k_{t}+\left(k_{t+1}-k_{t}\right)\left[1+\Psi\left(\frac{k_{t+1}-k_{t}}{k_{t}}\right)\right]$ is gross investment. The agent also faces the following collateral constraint:

$$
q_{t}^{b} b_{t+1}-\phi R_{t}\left(w_{t} L_{t}+p_{t} v_{t}\right) \geq-\kappa q_{t} k_{t+1}
$$

In the constraints $(2)$ and $(3), w_{t}$ is the wage rate, $q_{t}^{b}$ is the price of bonds and $q_{t}$ is the price of domestic capital. The price of bonds is exogenous and satisfies $q_{t}^{b}=1 / R_{t}$, while $w_{t}$ and $q_{t}$ are endogenous prices that are taken as given by the representative agent and satisfy standard market optimality conditions: The price of capital equals the marginal cost of investment, $q_{t}=\partial i_{t}\left(\bar{k}_{t+1}, \bar{k}_{t}\right) / \partial\left(\bar{k}_{t+1}\right)$, and the wage rate equals the marginal disutility of labor, $w_{t}=\partial N\left(\bar{L}_{t}\right) / \partial \bar{L}_{t}$, where variables with bars are "market averages" taken as given by the representative agent but equal to the representative agent's choices at equilibrium.

The collateral constraint (3) implies that credit markets are imperfect. In particular, lenders impose a credit constraint in the form of the margin requirement proposed by Aiyagari and Gertler (1999): The economy's total debt, including both debt in one-period bonds and in within-period working capital loans, cannot exceed a fraction $\kappa$ of the "marked-to-market" value of capital (i.e. $\kappa$ imposes an upper bound on the leverage ratio). Both interest and principal on working capital loans enter in the constraint because these

${ }^{7}$ Specifying the capital adjustment cost in terms of net investment, instead of gross investment, yields a more tractable recursive formulation of the economy's optimization problem that preserves Hayashi's (1982) results regarding the conditions that equate marginal and average Tobin $Q$. 
are within-period loans, and thus lenders consider that the market value of the assets offered as collateral must cover both components.

The collateral constraint is not derived here from an optimal credit contract. Instead, the constraint is imposed directly as in the models with endogenous credit constraints examined by Kiyotaki and Moore (1997), Aiyagari and Gertler (1999), and Kocherlakota (2000). Still, a credit relationship with a constraint like (3) could result, for example, from an environment in which limited enforcement prevents lenders to collect more than a fraction $\kappa$ of the value of a defaulting debtor's assets. As we explain below, in states of nature in which (3) binds, the model produces endogenous premia over the world interest rate at which borrowers would agree to contracts which satisfy (3).

\subsection{Competitive Equilibrium \& Credit Channels}

A competitive equilibrium for the small open economy is defined by stochastic sequences of allocations $\left[c_{t}, L_{t}, k_{t+1}, b_{t+1}, v_{t}, i_{t}\right]_{0}^{\infty}$ and prices $\left[q_{t}, w_{t}\right]_{0}^{\infty}$ such that: (a) the representative firmhousehold maximizes SCU subject to (2) and (3), taking as given wages, the price of capital, the world interest rate, and the initial conditions $\left(k_{0}, b_{0}\right)$, (b) wages and the price of capital satisfy $q_{t}=\partial i_{t}\left(\bar{k}_{t+1}, \bar{k}_{t}\right) / \partial\left(\bar{k}_{t+1}\right)$ and $w_{t}=\partial N\left(\bar{L}_{t}\right) / \partial \bar{L}_{t}$ and (c) the representative agent's choices satisfy $\bar{k}_{t}=k_{t}$ and $\bar{L}_{t}=L_{t}$.

In the absence of credit constraints, the competitive equilibrium is the same as in a standard DSGE-SOE model. In fact, removing also imported inputs, the model collapses into a model nearly identical to the models of Numeyer and Perri (2005) or Uribe and Yue (2006). The credit constraints distort the equilibrium by introducing two credit-channel effects. One of these effects is reflected in external financing premia affecting the cost of borrowing in bonds and working capital and the equity premium, and the second is the debt-deflation process. These credit-channel effects can be analyzed using the optimality conditions of the competitive equilibrium.

The optimality conditions of the representative agent's problem yield the following Euler equation for $b_{t+1}$ :

$$
0<1-\left(\mu_{t} / \lambda_{t}\right)=E_{t}\left[\left(\lambda_{t+1} / \lambda_{t}\right) R_{t+1}\right] \leq 1
$$

where $\lambda_{t}$ is the non-negative Lagrange multiplier on the date-t budget constraint (2), which equals also the lifetime marginal utility of $c_{t}$, and $\mu_{t}$ is the non-negative Lagrange multiplier on the collateral constraint (3). It follows from (4) that, when the collateral constraint binds, the economy faces an endogenous external financing premium on the effective real interest rate at which it borrows $\left(R_{t+1}^{h}\right)$ relative to the world interest rate. This expected external financing premium on debt (EFPD) is given by:

$$
E_{t}\left[R_{t+1}^{h}-R_{t+1}\right]=\frac{\mu_{t}+\operatorname{cov}\left(\lambda_{t+1}, \varepsilon_{t+1}^{R}\right)}{E_{t}\left[\lambda_{t+1}\right]}, \quad R_{t+1}^{h} \equiv \frac{\lambda_{t}}{E_{t}\left[\lambda_{t+1}\right]}
$$

This premium can be viewed as the premium at which the SOE would choose debt amounts that satisfy the collateral constraint with equality in a credit market in which the constraint is not imposed directly. 
In the canonical DSGE-SOE model, international bonds are a risk-free asset and $\mu_{t}=0$ for all $t$, so there is no premium. In the model examined here, if the collateral constraint binds, there is a direct effect by which the multiplier $\mu_{t}$ increases EFPD. In addition, there is an indirect effect that pushes in the same direction because a binding credit constraint makes it harder to smooth consumption, and hence the covariance between marginal utility and the world interest rate is likely to increase.

The effects of the EFPD on asset pricing can be derived from the Euler equation for capital. Solving forward this equation, taking into account that at equilibrium $q_{t}$ equals the marginal cost of investment, yields the following:

$$
\begin{gathered}
q_{t}=E_{t}\left[\sum_{j=0}^{\infty}\left(\prod_{i=0}^{j}\left(\frac{1}{\tilde{R}_{t+i+1}^{t+i}}\right)\right)\left(d_{t+1+j}\right)\right], \\
\tilde{R}_{t+i+1}^{t+i} \equiv \frac{\left(\lambda_{t+i}-\kappa \mu_{t+i}\right)}{\lambda_{t+i+1}}, \quad d_{t+1+j} \equiv \exp \left(\varepsilon_{t+1+j}^{A}\right) F_{1}\left(k_{t+1+j}, L_{t+1+j}, v_{t+1+j}\right)-\delta+\left(\frac{z_{t+1+j}}{k_{t+1+j}}\right)^{2} \Psi^{\prime}\left(\frac{z_{t+1+j}}{k_{t+1+j}}\right)
\end{gathered}
$$

Thus, the price of capital equals the expected present discounted value of future dividends $(d)$, discounted at a rate that reflects the effect of the collateral constraint.

The above asset pricing formula can be simplified further by combining the Euler equations for bonds and capital to obtain the following expression for the equity premium (the expected excess return on capital, $R_{t+1}^{q} \equiv\left(d_{t+1}+q_{t+1}\right) / q_{t}$, relative to $\left.R_{t+1}\right)$ :

$$
E_{t}\left[R_{t+1}^{q}-R_{t+1}\right]=E_{t}\left[R_{t+1}^{h}-R_{t+1}\right]-\frac{\mu_{t} \kappa+C O V_{t}\left(\lambda_{t+1}, R_{t+1}^{q}\right)}{E_{t}\left[\lambda_{t+1}\right]}
$$

This expression collapses to the standard equity premium if the collateral constraint does not bind and the world interest rate is deterministic. As Mendoza and Smith (2006) explained, when the collateral constraint binds it induces direct and indirect effects on the equity premium similar to those affecting EFPD. The two premia are not the same, however, because in the equity premium the direct effect of the binding collateral constraint on EFPD is reduced by the term $\mu_{t} \kappa / E_{t}\left[\lambda_{t+1}\right]$, which measures the marginal benefit of being able to borrow more by holding an additional unit of capital. There is also a new element in the indirect effect that is not present in the EFPD, and is implicit in the covariance between $\lambda_{t+1}$ and $R_{t+1}^{q}$ : A binding collateral constraint makes it harder for agents to smooth consumption and self-insure, and hence this covariance term is likely to become more negative when the constraint binds, thereby increasing the equity premium.

Given the result in (7), the asset pricing condition (6) can be re-written as:

$$
q_{t}=E_{t}\left(\sum_{j=0}^{\infty}\left[\prod_{i=0}^{j}\left(\frac{1}{E_{t}\left[R_{t+1+i}^{q}\right]}\right)\right] d_{t+1+i}\right)
$$

It follows then from (7) and (8) that, as Aiyagari and Gertler (1999) showed, higher expected returns when the collateral constraint binds at present, or is expected to bind in the future, increase the discount rate of dividends and lower asset prices in the present. 
The external financing premium on working capital financing is easy to identify in the optimality conditions for factor demands:

$$
\begin{aligned}
& \exp \left(\varepsilon_{t}^{A}\right) F_{2}\left(k_{t}, L_{t}, v_{t}\right)=w_{t}\left[1+\phi\left(r_{t}+\left(\frac{\mu_{t}}{\lambda_{t}}\right) R_{t}\right)\right] \\
& \exp \left(\varepsilon_{t}^{A}\right) F_{3}\left(k_{t}, L_{t}, v_{t}\right)=p_{t}\left[1+\phi\left(r_{t}+\left(\frac{\mu_{t}}{\lambda_{t}}\right) R_{t}\right)\right]
\end{aligned}
$$

These are standard conditions equating marginal products with marginal costs. In the righthand-side of (9) and (10), the term $\left(\frac{\mu_{t}}{\lambda_{t}}\right) R_{t}$ reflects the increase in the effective marginal financing cost of working capital caused by a binding collateral constraint. This external financing premium on working capital represents the excess over the world interest rate at which domestic agents in a competitive world market of working capital loans would find it optimal to agree to contracts that satisfy constraint (3) voluntarily.

The second credit channel present in the model, the debt-deflation mechanism, is harder to illustrate than the external financing premia because of the lack of closed-form solutions, but it can be described intuitively: When the collateral constraint binds, agents respond to "margin calls" from lenders by fire-selling capital (i.e., by reducing their demand for equity). However, when they do this, they face an upward-sloping supply of equity because of Tobin's $Q$. Thus, at equilibrium it is optimal to lower investment given the reduced demand for equity and higher discounting of future dividends, and hence equilibrium equity prices fall. If the credit constraint was set as an exogenous fixed amount, these would be the main adjustments. But with the endogenous collateral constraint, if the constraint was binding at the initial (notional) levels of the price of capital and investment, it must be more binding at lower prices and investment levels, so another round of margin calls takes place and Fisher's debt-deflation mechanism is set in motion. Moreover, the Fisherian deflation causes a sudden increase in the financing cost of working capital, lowering factor allocations and output.

Interestingly, the effects of the debt-deflation mechanism are non-monotonic, because they are weaker at the extremes in which the SOE can collateralize all of its assets $(\kappa=1)$ or cannot borrow at all $(\kappa=0)$ than in the cases in between. When $\kappa=0$ there can be no debtdeflation, since the constraint does not respond to asset values (i.e., it becomes an exogenous credit limit). On the other hand, when $\kappa=1$ there is no direct effect from the collateral constraint on the equity premium, which leaves only the indirect covariance effects to distort investment and the price of capital relative to the equilibrium with perfect credit markets. In the limiting case without uncertainty, the indirect effects vanish, and $\kappa=1$ removes all distortions on investment and the price of capital, and hence there is no debt-deflation mechanism again. Consumption and debt still adjust, but they do so as they would with an exogenous credit constraint. Hence, for the debt-deflation mechanism to operate, credit markets must allow borrowers to leverage their assets but only to some degree.

Mendoza (2006) illustrates the above arguments using a simple numerical example based on a deterministic version of the model. This example is comparable to the one conducted by Kocherlakota (2000). Mendoza found large amplification effects of the collateral constraint on output and asset prices. In contrast, Kocherlakota found small amplification effects, using a borrowing constraint of the form $b_{t+1} \geq q_{t} x_{t}$, where $x_{t}$ can be a fixed factor (e.g., land) or physical capital. The two sets of results are consistent, however, 
because the case with land prevents declines in $x_{t}$ from compounding with the decline in asset prices in the debt-deflation dynamics, and with capital, the constraint $b_{t+1} \geq q_{t} x_{t}$ implies $\kappa=1$ (which under perfect foresight removes the debt-deflation mechanism).

It is also important to note that a variety of actual contractual arrangements can produce debt-deflation dynamics. The collateral constraint (3) resembles most directly a contract with a margin clause. This clause requires borrowers to surrender the control of collateral assets when the contract is entered, and gives creditors the right to sell them when their market value falls below the contract value. Other widely used arrangements that can trigger debt-deflation dynamics without explicit margin clauses include value-at-risk strategies of portfolio management used by investment banks, and mark-to-market capital requirements imposed by regulators. For example, if an aggregate shock hits capital markets, value-at-risk estimates increase and lead investment banks to reduce their exposure, but since the shock is aggregate, the resulting sale of assets increases price volatility and leads value-at-risk models to require further portfolio adjustments. Mechanisms like these played a central role in the Russian/LTCM crisis of 1998 and the U.S. credit crisis of 2007-2008.

\section{Functional Forms and Calibration}

\subsection{Functional Forms and Numerical Solution}

The quantitative analysis uses a benchmark calibration based on Mexican data. The functional forms of preferences and technology are the following:

$$
\begin{gathered}
u\left(c_{t}-N\left(L_{t}\right)\right)=\frac{\left[c_{t}-\frac{L_{t}^{\omega}}{\omega}\right]^{1-\sigma}-1}{1-\sigma}, \quad \sigma, \omega>1, \\
v\left(c_{t}-N\left(L_{t}\right)\right)=\gamma\left[\operatorname{Ln}\left(1+c_{t}-\frac{L_{t}^{\omega}}{\omega}\right)\right], \quad 0<\gamma \leq \sigma, \\
F\left(k_{t}, L_{t}, v_{t}\right)=A k_{t}^{\beta} L_{t}^{\alpha} v_{t}^{\eta}, \quad 0 \leq \alpha, \beta, \eta \leq 1, \quad \alpha+\beta+\eta=1, \quad A>0, \\
\Psi\left(\frac{z_{t}}{k_{t}}\right)=\frac{a}{2}\left(\frac{z_{t}}{k_{t}}\right), \quad a \geq 0
\end{gathered}
$$

The utility and time preference functions in (11) and (12) are standard from DSGE-SOE models. The parameter $\sigma$ is the coefficient of relative risk aversion, $\omega$ determines the wage elasticity of labor supply, which is given by $1 /(\omega-1)$, and $\gamma$ is the semi-elasticity of the rate of time preference with respect to composite good $c-N(L)$. The restriction $\gamma \leq \sigma$ is a

condition required to ensure that SCU supports a unique, invariant limiting distribution of bonds and capital (see Epstein (1983)). The Cobb-Douglas technology (13) is the production function for gross output. Equation (14) is the net investment adjustment cost function. Following Hayashi (1982), the production and adjustment cost functions are set to be linearly homogeneous in their arguments. 
The model is solved numerically by representing the equilibrium in recursive form and using a non-linear global solution method with the collateral constraint imposed as an occasionally binding inequality constraint (see Mendoza and Smith (2006) and Arellano and Mendoza (2003) for details on algorithms for solving DSEG-SOE models with incomplete markets and collateral constraints). The endogenous state variables are $k$ and $b$. These are chosen from discrete grids of NK non-negative values of the capital stock, $K=\left\{k_{1}<k_{2}<\ldots<\right.$ $\left.k_{N K}\right\}$, and NB values of bond positions, $B=\left\{b_{1}<b_{2}<\ldots<b_{N B}\right\}$. The exogenous states are the realizations of shocks in the triple $e=\left(\varepsilon^{A}, \varepsilon^{R}, \varepsilon^{P}\right)$. The shocks follow a joint Markov process, which defines the set $E$ of all triples of possible realizations of the shocks and their one-step transition probability matrix $\pi$. Hence, the state space of the problem is defined by all triples $(k, b, e)$ in the set $K \times B \times E$. In the numerical solutions reported in Section 4, we set $N K=60$ and $N B=80$, with both grids evenly spaced. Also, we use 2 realizations for each Markov shock, so there are 8 triples of realizations of shocks. Hence, the discrete state space of the model has $60 \times 80 \times 8$ coordinates.

\subsection{Calibration}

The values assigned to the model's parameters are listed in Table 1 . This calibration is set so that the deterministic stationary equilibrium matches key averages from Mexican data. We adopt three assumptions to make the calibration easier to compare with typical DSGE-SOE calibrations: (1) $\phi=0$ in the deterministic steady state (otherwise working capital payments distort factor shares), (2) the collateral coefficient does not bind at the deterministic steady state, and (3) the CRRA coefficient is set to $\sigma=2$.

The measure of gross output $(y)$ in Mexican data that is consistent with the one in the model is the sum of GDP plus imported inputs. The data for these variables are available quarterly (at annual rates) starting in 1993. Using data for the period 1993:Q1-2005:Q2, the annualized average ratio of GDP to gross output $(g d p / y)$ is 0.896 and the ratio of imported inputs to GDP $(p v / g d p)$ is 0.114 . The average share of imported inputs in gross output is 0.102 , hence $\eta=0.102$. This factor share, combined with the 0.66 labor share on GDP from Garcia (2005) implies the following factor shares for the production function (13): $\alpha=\left(\frac{0.66}{1+(p v / g d p)}\right)=0.592$ and $\beta=1-\alpha-\eta=0.306 .^{8}$

We also use Garcia's (2005) estimates of Mexico's capital stock, together with our measure of $y$, to construct an estimate of the capital-gross output ratio $(k / y)$ and to set the value of the depreciation rate. He used annual National Accounts investment data for the period 1950-2000 and the perpetual inventories method to construct a time series of the capital-GDP ratio. The average capital-GDP ratio for the $1980-2000$ period is 1.88 with a 1980 point estimate of 1.56 . Using these annual benchmarks, we constructed a quarterly capital stock series compatible with the quarterly gross output estimates (starting in 1980 because quarterly investment data, again at annual rates, are available as of 1980:Q1). The annualized quarterly capital stock estimates match Garcia's annual benchmarks by setting

\footnotetext{
${ }^{8}$ The actual share of labor income in GDP is about $1 / 3$ in National Accounts data but Garcia showed that there are measurement problems in separating capital and labor incomes in the National Accounts. Estimating factor shares using household survey data he estimated the labor share at about $2 / 3 \mathrm{rds}$, which is in line with the usual estimates for the U.S. and other countries.
} 
the initial capital-GDP ratio to 1.45 and the depreciation rate to 8.8 percent per year. The 1980:Q1-2005:Q2 average of $k / y$ is 1.758 . Combined with the 0.088 depreciation rate, this value of $k / y$ yields an average investment-gross output ratio $(i / y)$ of 15.5 percent.

In the deterministic stationary state, imported input prices and the real interest rate take their mean values $p$ and $R$. The value of $p$ is set equal to the ratio of the averages of the ratios of imported inputs to gross output at current and constant prices, which is 1.028. The mean value of the annual gross real interest rate is derived by imposing the values of $\beta$, $(i / y)$, and $\delta$ on the Euler equation for capital evaluated at steady state and solving for $R$. The resulting expression yields $R=1+[\delta(\beta-(i / y))] /(i / y)=1.086$. A real interest rate of 8.6 percent is relatively high, but in this calibration it represents the implied real interest rate that, given the values of $\delta$ and $\beta$, supports Mexico's average investment-gross output ratio as a feature of the deterministic steady state of a standard SOE model. Note also that with this calibration strategy the deterministic steady state also matches Mexico's average investment-GDP ratio of 17.2 percent.

The model's optimality condition for labor supply equates the marginal disutility of labor with the real wage, which at equilibrium is equal to the marginal product of labor. This condition reduces to: $L_{t}^{\omega}=\alpha \exp \left(\varepsilon_{t}^{A}\right) F(\cdot)$. Using the logarithm of this expression, our estimate of gross output, and Mexican data on employment growth, the implied value of the exponent of labor supply in utility is $\omega=1.846$. This value is similar to those typically used in DSGE-SOE models (e.g. Mendoza (1991), Uribe and Yue (2006)).

Since aggregate demand in the data includes government expenditures, the model needs an adjustment to consider these purchases in order for the deterministic steady state to match the actual average private consumption-GDP ratio of 0.65 . This adjustment is done by setting the deterministic steady state to match the observed average ratio of government purchases to GDP (0.11), assuming that these government purchases are unproductive and paid out of a time-invariant, ad-valorem consumption tax. The tax is equal to the ratio of the GDP shares of government and private consumption, $0.11 / 0.65=0.168$, which is very close to the statutory value-added tax rate in Mexico. Since this tax is time invariant, it does not distort the intertemporal decision margins and any distortion on the consumptionleisure margin does not vary over the business cycle.

Given the preference and technology parameters set in the previous paragraphs, the optimality conditions for $L$ and $v$ and the steady-state Euler equation for capital are solved as a nonlinear simultaneous equation system to determine the steady state levels of $k, L$, and $v$. Given these, the levels of gross output and GDP are computed using the production function and the definition of GDP, and the level of consumption is determined by multiplying GDP times the average consumption-GDP ratio in the data. The value of $\gamma$ follows then from the steady-state consumption Euler equation, which yields $\gamma=\frac{\ln (R)}{\ln \left(1+c-\omega^{-1} L^{\omega}\right)}=0.0166$. As is typical in calibration exercises with SCU preferences (see Mendoza (1991)), the value of the time preference coefficient is very low, suggesting that the "impatience effects" introduced by the endogenous rate of time preference have negligible quantitative implications on business cycle dynamics. Finally, the steady-state foreign asset position follows from the budget constraint (eq. (2)) evaluated at steady state. This implies a ratio of net foreign assets to GDP of about -0.86 . 
Next we calibrate the stochastic process of the exogenous shocks and compute Mexico's business cycle moments. Table 2 summarizes key features of Mexico's business cycles and the Sudden Stop of 1995. The Table provides indicators of business cycle variability, comovement and persistence of macroeconomic time series using the Hodrick-Prescott filter to detrend the data. The Table also reports moments for estimates of the model's three exogenous shocks. TFP shocks are measured as the cyclical component of a TFP estimate constructed using the production function (13), together with the capital stock and gross output estimates discussed earlier, the calibrated factor shares, and observed data on $L$ and $v$ (see Mendoza (2006) for details). The price shocks are deviations from trend of the relative price of imported inputs, defined as the deflator of imported inputs divided by the exports deflator (so as to remove effects from changes in the nominal exchange rate or in nontradables prices). Interest rate shocks are the cyclical component of Uribe and Yue's (2006) measure of Mexico's real interest rate in world capital markets.

The business cycle moments reported in Table 2 are in line with well-known business cycle facts for emerging economies: Investment is more variable than GDP, private consumption is also more variable than GDP (although nondurables consumption is less variable than GDP), all variables exhibit positive first-order autocorrelations, consumption and investment are positively correlated with GDP and the external accounts are negatively correlated with GDP. In addition, the Table shows that both imported inputs and equity prices are significantly more variable than GDP and procyclical.

The model's exogenous shocks follow a joint Markov process that approximates their time-series processes in the data. In the data, $\varepsilon^{A}, \varepsilon^{R}$ and $\varepsilon^{P}$ follow stationary $\operatorname{AR}(1)$ processes nearly independent of each other, except for a statistically significant, negative correlation between $\varepsilon^{R}$ and $\varepsilon^{P}$. Table 2 lists the standard deviations and first-order autocorrelations of the shocks. The correlation between interest rate and TFP shocks is -0.669 . Note that the 1995 Sudden Stop coincided with sizable shocks, but we will show below that Sudden Stops are possible in the model even with one-standard-deviation shocks. Also, typical endogeneity caveats apply to our estimates of $\varepsilon^{R}$, because of the link between country risk and business cycles, and $\varepsilon^{A}$, because of factors that affect measured TFP in addition to imported inputs, such as capacity utilization and factor hoarding. As a result, the "large" TFP and interest rate shocks reported for the 1995 Sudden Stop probably overestimate the true exogenous shocks that occurred that year.

The joint Markov process is a parsimonious chain with two-point realization vectors for each shock. Each realization is set equal to plus/minus one-standard deviation of the corresponding shock. The Markov transition probability matrix is constructed following the simple persistence rule. This imposes the condition that the first-order autocorrelation of the two correlated shocks $\left(\varepsilon^{A}\right.$ and $\left.\varepsilon^{R}\right)$ be the same, which is very much in line with the data since $\rho\left(\varepsilon^{R}\right)=0.572$ and $\rho\left(\varepsilon^{A}\right)=0.537$.

Two parameter values remain to be determined: the adjustment cost coefficient $a$ and the working capital coefficient $\phi$. We set these using the Simulated Method of Moments (SMM) so that the model matches the observed ratio of the standard deviation of Mexico's gross investment relative to GDP (3.6) and a mean ratio of working capital to GDP of $1 / 5$, in a simulation where the collateral constraint does not bind. This yields the values $a=2.75$ and $\phi=0.26$. This is a reasonable approach to calibrate $a$ because this parameter does not 
affect the deterministic steady state, but it affects the variability of investment. The working capital-GDP target of 20 percent is an approximation to actual data. Data on working capital financing for Mexico are not available, but the 1994:Q1-2005:Q1 average of total credit to private nonfinancial firms as a share of GDP was 24.4 percent. Note, however, that this measure includes financing at all maturities and for all uses, so it overestimates actual working capital financing. On the other hand, these data include the 1995-2002 period in which Mexican banks were being re-capitalized after the 1994 crisis, and credit declined sharply for "abnormal" reasons that bias the average credit-output ratio downwards.

It is also important to note that $\phi=0.26$ is significantly lower than the working capital coefficients used in the DSGE-SOE models of Neumeyer and Perri (2005) and Uribe and Yue (2006). As Oviedo (2004) showed, with low working capital coefficients, the working capital channel has very weak effects on business cycle moments. Hence, the role of working capital in this model is limited to the amplification and asymmetry that it contributes to when the collateral constraint binds. Its effect on regular business cycle volatility is negligible.

\section{Results of the Quantitative Analysis}

This section reports the results of a quantitative analysis that evaluates the model's ability to account for the stylized facts of Sudden Stops, and the magnitude of the amplification and asymmetry in the responses of macroeconomic aggregates to shocks induced by the collateral constraint.

\subsection{Long Run Business Cycle Moments}

The first result we establish is that long-run business cycle moments are largely unaffected by the collateral constraint. To make this point, we compare in Table 3 the business cycle moments of a frictionless economy without collateral constraints (Panel I) with those from two scenarios with different values of $\kappa$ in which the constraint binds in some states of nature (Panels II with $\kappa=0.3$ and III with $\kappa=0.2$ ). These moments are computed using the model's limiting distribution of $k, b$, and $e$ in each scenario. The value of $\kappa=0.2$ was chosen to match the observed frequency of Sudden Stops (see 4.2 below), and $\kappa=0.3$ is shown for comparison.

The moments listed in Panel I show that the model does well at accounting for Mexico's key business cycle regularities. The model overestimates the variability of GDP (3.9 percent in the model v. 2.7 percent in the data), but scaling by the variability of output the model does a fair job at matching the variability of the other macro aggregates, and the GDPcorrelations and first-order autocorrelations are generally in line with the data. Note in particular that the model does well at accounting for three moments that the RBC-SOE literature emphasizes: consumption is more variable than GDP, the interest rate and GDP are negatively correlated, and net exports are countercyclical. Moreover, in contrast with the findings of Garcia, Pancrazi and Uribe (2006), the model does not yield near-unit-root behavior in the net exports-GDP ratio. In fact, it nearly matches the actual first-order autocorrelation of this variable (0. 769 in the model v. 0.797 in the data).

Panels II and III show that long-run business cycles in economies with collateral constraints are very similar to those observed in the frictionless economy of Panel I. The 
credit friction only has large effects on the moments directly influenced by it: the leverage ratio, the ratio of foreign assets to GDP and the net exports-GDP ratio. The means of the leverage ratio and the foreign assets ratio rise, and the mean of the net exports-GDP ratio falls, the variability of the three declines, and all three become more countercyclical.

A key feature of the model behind the result that long-run business cycle moments in Panels II and III do not differ much from those of the frictionless economy in Panel I is the precautionary savings motive. The high-leverage states at which the credit constraint binds are reached after cyclical dynamics in response to sequences of realizations of the shocks lead the leverage ratio to approach its ceiling. Because of the curvature of the constant-relativerisk-aversion period utility function, agents accumulate precautionary savings to self insure against the risk of large consumption collapses in these scenarios. Note that precautionary savings are present even without the collateral constraint, because even with perfect credit markets this DSGE-SOE model has incomplete markets. Hence the average $b / g d p$ ratio with perfect credit markets at about -33 percent is almost 53 percentage points higher than in the deterministic steady state. With the collateral constraint at $\kappa=0.2$, the average $b / g d p$ ratio climbs to -10 percent

\subsection{Amplification \& Asymmetry with the Collateral Constraint}

The second result we demonstrate is that the collateral constraint produces significant amplification and asymmetry in the responses of macro-economic aggregates to shocks. To show this result, Table 4 reports amplification coefficients for model simulations with the collateral constraint. The amplification coefficients correspond to differences in the response of each variable in the economy with the collateral constraint relative to the economy with perfect credit markets, in percent of the latter, for a common $(k, b, e)$ triple. Since there is an amplification coefficient for each triple $(k, b, e)$ in the state space, we report averages computed using the model's ergodic distribution. The Table shows a set of coefficients for Sudden Stop (SS) states, defined in a manner analogous to those used in the empirical literature (e.g. Calvo et al. (2006)). In particular, SS states are those in which the collateral constraint binds (with positive long-run probability) and the net exports-GDP ratio is at least two percentage points above the mean. Non-SS states include all triples in the state space outside the SS set. The long-run probability of hitting SS states and the average debt ratio at which this happens are shown in the last two rows of the Table.

Panel (1) of the Table reports amplification coefficients for the baseline case with $\kappa=0.2$. With this upper bound on leverage, the probability of Sudden Stops is 3.3 percent, which matches the frequency of Sudden Stops in the cross-country panel dataset of Calvo et al. (2006). The SS column shows that when the economy hits a Sudden Stop, the collateral constraint amplifies significantly the response of all macroeconomic aggregates to shocks, relative to what is observed in the same $(k, b, e)$ states in the economy without credit frictions. The increased responsiveness of the aggregates ranges from a decline in GDP below trend that is about 1.1 percent larger to a collapse in investment that is almost 12 percentage points larger. Scaling by the cyclical variability of each aggregate listed in Panel III of Table 3, these excess responses imply business cycles that are larger than typical cycles by factors of about $1 / 3$ for GDP to 1.4 for the net exports-GDP ratio. 
The model's baseline amplification coefficients in Panel (1) of Table 4 are significantly larger than those computed by Kocherlakota (2000). He found that, varying the share of capital from 0.1 to 0.3 , the amplification coefficients were small, ranging from 0.15 to 0.35 for output (v. 1.13 in the model) and 0.004 to 0.008 for asset prices (v. 2.9 in the model). As explained earlier, Kocherlakota's experiments produce weak amplification because they focus in cases in which either the collateral asset is in fixed supply (which weakens the debtdeflation mechanism), or capital can be pledged as collateral up to 100 percent of its value (which under perfect foresight removes the debt-deflation mechanism completely).

The asymmetry of the amplification effects is illustrated by the stark comparison of the amplification coefficients across SS and non-SS columns. In non-SS states, the responses of macro-aggregates are about the same with the collateral constraint as with perfect credit markets, and scaling by the variability of each aggregate the difference across the two economies is negligible. Since Sudden Stop events are low probability events in the long-run, the business cycle moments shown in Table 3 reflect mainly these non-SS states in which there is no amplification due to the credit constraint, and this is consistent with the previous finding showing that the model with the collateral constraint displays business cycle moments very similar to those of the frictionless economy. A corollary of this result is that relatively rare Sudden Stops coexist with the more frequent, normal business cycles summarized in the moments of Table 3. It is also worth noting that the responses in the SS and non-SS columns are produced by shocks that are at most one-standard-deviation in size (as defined in the vector of realizations of the Markov chain), and that the exogenous shocks hitting the economies with and without the collateral constraint in each of the two columns are identical. Thus, the model displays significant amplification and asymmetry in response to shocks that are relatively small, and it has the feature that symmetric shocks produce asymmetric responses, the extreme case of which is a Sudden Stop.

Panels (2) to (5) of Table 4 show that the result indicating that the collateral constraint induces significant amplification and asymmetry in the macroeconomic effects of exogenous shocks is robust to several parameter changes. Panels (2) and (3) report results for $\kappa=0.3$ and $\kappa=0.15$ respectively. Panel (4) lowers the net exports-GDP threshold ratio used to define Sudden Stops from an increase of two percentage points above the mean to zero. Panel (5) removes working capital financing by setting $\phi=0$.

Increasing (reducing) $\kappa$ has small effects on the amplification coefficients, but it reduces (increases) the amplification effect on the leverage ratio and the probability of Sudden Stops. Lowering the net exports-GDP threshold to zero weakens the amplification coefficients somewhat, but again the largest effect is on the probability of Sudden Stops, which rises sharply when the threshold used to define them is lowered significantly. Still, in all these scenarios there is significant amplification and asymmetry. In the scenario without working capital, however, the model cannot generate any amplification in GDP and factor allocations, and the probability of Sudden Stops (keeping $\kappa=0.2$ ) is very low. This is because without working capital, factor allocations and output are not affected contemporaneously by the collateral constraint (capital is predetermined and the external financing premium on optimal factor demands is not present, so labor and intermediate goods are not affected by the collateral constraint). The rest of the macro-aggregates continue to display significant amplification and asymmetry, although the amplification coefficients are smaller than in the scenarios shown in the other panels. Thus, these results highlight the importance of the 
collateral constraint limiting access to working capital for the model's ability to produce significant amplification and asymmetry.

\subsection{Can the Model Explain Observed Sudden Stop Dynamics?}

The numerical simulations can also be used to evaluate the model's ability to account for the actual dynamics of Sudden Stop events in Figure 1 reviewed in the Introduction. To this end, we conduct a 10,000-period stochastic time series simulation of the model, and use the resulting artificial data to construct five-year event windows centered on SS events. Figure 2 shows the SS windows for GDP, C, I, Tobin's $Q$, and $N X Y$. To match the methodology used in Figure 1, each window includes the median across the SS events identified in the 10,000 period simulation. We also include for comparison + and - onestandard-deviation bands, the actual event window observations from Figure 1, and the observations from Mexico's 1995 Sudden Stop. To be consistent with Calvo et al.'s (2006) definition of systemic SS events with mild and large output collapses, a Sudden Stop event is identified as a situation in which the collateral constraint binds, output is at least one standard deviation below trend, and the net exports-GDP ratio is at least one standard deviation above trend.

The event windows in Figure 2 show that the model replicates most of the key features of the dynamics of actual SS events, except for the magnitude of the decline in asset prices. The model predicts that Sudden Stops are preceded by periods of economic expansion, with GDP, $C$ and $I$ above trend and $N X Y$ running deficits at $t$-2 and $t-1$. In the date of the SS events (date $t$ ), the model matches very closely the magnitude of the declines in $G D P, C$, and $I$. The reversal in $N X Y$ between $t-1$ and $t$ is also very similar to the one in the data, but the levels in the model overestimate those in the data. The model is also consistent with the data in predicting a slow recovery in dates $t+1$ and $t+2$. With regard to Tobin's $Q$, the model's dynamics are qualitatively correct, but quantitatively the decline in asset prices is about 40 percent the size of the actual decline. Relative to the Mexican SS event, the model again matches very well the magnitude of the declines in GDP and $C$ at date $t$, but it underestimates the pre-Sudden Stop boom and the size of the reversal in $N X Y$.

Figure 3 shows event windows for true TFP (i.e. the productivity shock $\varepsilon^{A}$ ) and for the model's Solow residual, defined as $s \equiv g d p /\left(k^{\beta /(1-\eta)} L^{\alpha /(1-\eta)}\right)$. In the baseline scenario with $\kappa=0.2$, the two are very similar except on the date of SS events. When Sudden Stops occur, the Solow residual falls more than true TFP. Thus, the model is also consistent with the data in predicting that part of the decline in GDP observed during SS events cannot be accounted for by changes in measured capital and labor, and that this decline in the Solow residual overestimates actual TFP (albeit the difference is not large). However, it is also important to acknowledge that true TFP still has to fall for the output decline to be realistic, and the reason why TFP would fall like this when a Sudden Stop hits remains an open question beyond the scope of this paper.

In summary, the model with the collateral constraint accounts for several key features of Sudden Stops. Large and infrequent recessions take place in response to shocks of standard magnitude when the economy is highly leveraged, and Sudden Stops are nested within normal business cycles. The economy arrives at these high-leverage states with positive long-run probability, and in these states binding collateral constraints cause large 
amplification, asymmetry and persistence in macroeconomic responses to shocks. One weakness, however, is that the decline in asset prices is smaller than the observed collapse, but it is worth recalling that this, as well as all the other Sudden Stop effects studied in this paper, are in response to one-standard-deviation shocks. Larger shocks would trigger larger responses. Moreover, even at $1 / 2$ the size of the actual price drop, the model generates significantly more asset price amplification than in previous studies (e.g. Kocherlakota $(2000))$.

\subsection{Sensitivity Analysis}

Figure 4 compares Sudden Stop event windows for the baseline economy (with $\kappa=0.2$ ) with those of three alternative specifications: (1) the scenario without working capital $(\phi=0)$, (2) a simulation with a higher share of imported inputs in production $(\eta=0.2 \mathrm{v}$. 0.1 in the baseline), and (3) a scenario with a higher value of $\omega$ (3 instead of 1.85), which implies a lower labor supply elasticity (0.5 instead of 1.2). The event dynamics observed in actual data are also included for comparison in Figure 4, and Figure 3 includes event windows comparing Solow residuals with true TFP in each of the three sensitivity analysis scenarios. Note that we consider relatively small changes in parameters because otherwise the economies differ sharply in debt and leverage dynamics, and this requires recalibrating $\kappa$ in order to study the effects of the occasionally binding collateral constraint. In contrast, with the parameter changes we study here, the value of $\kappa$ remains at 20 percent in all scenarios.

The simulation without working capital performs much worse than the baseline and the other alternatives in terms of its ability to account for observed Sudden Stop dynamics. Without working capital, the amplitude of the fluctuations observed in SS events is significantly smaller, but more significantly, the model fails to produce periods of economic expansion preceding Sudden Stops, as GDP, $C$ and $I$ are already below trend, and $N X Y$ is above trend, before the Sudden Stop hits. This occurs because SS events without working capital are preceded by periods of low and declining productivity (see Figure 3), instead of periods of high and increasing productivity as in the baseline. The expectation of declining productivity leads to a substantial decline in $I$ at almost 15 percentage points below trend and drops in $C$ and $I$ of about 2 percentage points below trend by $t-1$, and this results in a sharp increase in the trade surplus to about 2.5 percentage points of $G D P$ by the same date. For the same reason, labor and imported inputs fall sharply (instead of risinig) before the Sudden Stop hits, although again because the absence of working capital reduces the amplitude of the economy's business cycle, the declines in labor and imported inputs at date $t$ are much smaller than in the baseline. The output decline is not smaller at date $t$ because the large decline in $I$ at $t-1$ reduces the capital stock at $t$ and this enlarges the size of the output drop, which otherwise would be much smaller than in the baseline (in the baseline, $I$ rises at $t$ - 1 so the higher capital stock at $t$ contributes to offset the contractionary effect of the declines in labor and imported inputs). Thus, these results reaffirm the previous finding indicating that the collateral constraint limiting access to working capital financing plays a very important role in the model's performance.

The scenarios with higher imported inputs share and lower labor supply elasticity show that these parameters also play important roles. The shape of the SS dynamics is roughly the same as in the baseline, so the model's overall performance does not worsen as in the scenario without working capital, but the amplitude of the fluctuations changes. A higher 
share of imported inputs strengthens the production effects of all three shocks present in the model. As a result the declines in GDP, $C$, working capital, labor, and imported inputs are larger with the higher share of imported inputs, while the dynamics of $I$ and $Q$ are about the same as in the baseline. The fit with the data improves as the drops in output and consumption at date $t$ are nearly a perfect match to those observed in actual SS events. In addition, the simulation with the higher imported inputs share creates a much larger wedge between the Solow residual and true TFP (see Figure 3). An average decline of about 1.2 percent in true TFP when Sudden Stops hit translates into an average decline in the Solow residual that is almost twice as large. Thus, a higher share of imported inputs improves the model's ability to match observed Sudden Stop dynamics, with larger declines in production, consumption and factor allocations, and with a larger fraction of the output drop accounted for by the Solow residual.

The above results for higher $\eta$ are important because the baseline calibration value of $\eta=0.1$ is probably conservative. Evidence from other countries suggests that imported inputs can have much higher shares. Goldberg and Campa (2006) report ratios of imported inputs to total intermediate goods for 17 industrial countries that vary from 14 to 49 percent, with a median of 23 percent (the ratio for Mexico is about 1/4). Moreover, to the extent that domestically produced inputs are substitutes for imported inputs, and purchases of these domestic inputs require working capital financing, the scenario with the higher $\eta$ is likely to be closer to the one that is empirically relevant, because domestic inputs would respond to a similar amplification mechanism as the one affecting imported inputs. ${ }^{9}$

The model simulation with lower labor supply elasticity retains the same overall qualitative features of the Sudden Stop events of the baseline simulation: The simulation still produces SS events preceded by periods of expansion and followed by gradual recoveries. With the weakened response of labor supply, however, the amplitude of the fluctuations is smaller, and the gap between true TFP and the Solow residual when the Sudden Stop hits is narrower, so the model does not do as well as the baseline in terms of matching the dynamics observed in actual data. In contrast with what we observed in the exercise that changed the share of imported inputs, lowering the labor supply elasticity does affect the behavior of investment and asset prices, both of which exhibit smaller declines than in the baseline scenario. Thus, these results show that labor supply elasticity of about 1.2 , as in the baseline, or higher, is important for the model's ability to explain observed SS dynamics.

\section{Conclusions}

This paper shows that the quantitative predictions of an equilibrium business cycle model with an endogenous collateral constraint are consistent with key features of the Sudden Stop phenomenon. The constraint imposes an upper bound on the economy's leverage ratio by limiting total debt, including working capital loans, not to exceed a fraction of the market value of collateral assets. This constraint only binds in states of

\footnotetext{
${ }^{9}$ Extending the model to include domestic inputs, however, is a challenging task because it requires modeling supply and demand of these inputs with and endogenous price. The model can be modified following Mendoza and Yue (2008) to introduce the two inputs using an Armington aggregator, but the solution algorithm for the setup with occasionally binding, endogenous collateral constraints is harder to solve and runs against the curse of dimensionality.
} 
nature in which the leverage ratio is sufficiently high, and in turn these high-leverage states are an endogenous outcome of the model's business cycle dynamics.

The model's collateral constraint introduces a credit channel with two important distortions: one is in the form of external financing premia affecting the cost of borrowing in one-period debt and within-period working capital loans, and the second is Fisher's debtdeflation mechanism. This mechanism plays a key role in the ability of the model to explain Sudden Stops. When the leverage ratio is sufficiently high, shocks of standard magnitude that result in RBC-like responses under perfect credit markets trigger the collateral constraint. This causes a fall in investment and equity prices which tightens further the constraint and leads to a spiraling collapse of credit, asset prices and investment, a decline in consumption and a surge in the external accounts. Moreover, the binding credit limit hampers access to working capital, causing a contemporaneous decline in output and factor allocations.

This paper's quantitative analysis show that the long-run business cycle moments of economies with and without the collateral constraint differ marginally, while the mean responses to one-standard-deviation shocks conditional on Sudden Stop states with positive long-run probability differ sharply across the two economies. Thus, in contrast with findings of previous studies, the collateral constraint produces significant amplification and asymmetry in the responses of macroeconomic aggregates to shocks of standard magnitudes on the same exogenous factors that drive normal business cycles (TFP, interest rates and imported input prices). In addition, because of precautionary saving, Sudden Stops are infrequent events nested within normal business cycles in the stochastic stationary equilibrium. Thus, the model proposed here provides an explanation of Sudden Stops that does not rely on large, unexpected shocks, and integrates a theory of business cycles with a theory of Sudden Stops within the same DSGE framework.

A comparative event analysis of Sudden Stops in the data and in the model shows that the model matches key features of actual Sudden Stops. In particular, Sudden Stops in the model are preceded by periods of economic expansion and external deficits, followed by large recessions and reversals in the external accounts when Sudden Stops hit, and then followed by gradual recovery. Moreover, Solow residuals exaggerate the contribution of true TFP to the Sudden Stops' output drop. These results are robust to variations in the labor supply elasticity and the share of imported inputs in production. In contrast, the assumption that the collateral constraint limits access to working capital financing plays an important role.

An interesting extension of this framework would be to study a setup with "liability dollarization," in which foreign debt is denominated in a hard currency (i.e. tradable goods) but largely leveraged on assets and/or incomes in domestic currency and generated by nontradables industries. This is important to consider because Sudden Stops also featured large drops in the relative price of nontradables, and in many cases large nominal devaluations (with exceptions like Hong Kong 1998 and Argentina 1995). A large, exogenous devaluation can be viewed as the cause of a Sudden Stop in this situation, but an alternative is to model a debt-deflation mechanism operating through a fall in the relative price of nontradables. Durdu, Mendoza and Terrones (2008) study a model with this feature in a setup without capital accumulation and where the debt limit is a function of income rather than the value of capital. 
The findings of this paper suggest that the key to reducing the probability of Sudden Stops is in promoting the attainment of levels of financial development that weaken the contractual frictions behind collateral constraints. In contrast, taking as given the underlying uncertainty in the form of aggregate shocks to TFP, world interest rates and relative prices, tighter "marked-to-market" capital requirements or "value-at-risk" targets, designed to manage exposure to idiosyncratic risk, can be counterproductive and raise the probability of observing Sudden Stops. Other policy conclusions derived from this analysis relate to financial contagion and the desirability of holding large stocks of foreign reserves. In the setup of this paper, an economy can have solid domestic policies and competitive, open markets, and still reach a point of high leverage at which a Sudden Stop is caused by a relatively small foreign or domestic shock. If waiting for financial development to eliminate this problem seems naïve, and since tighter credit limits can make things worse, self insurance in the form of a sufficiently large stock of reserves can be a useful way of lowering the probability of Sudden Stops. The analysis by Durdu et al. (2008) provides evidence in favor of this argument. 


\section{References}

Aiyagari, S. Rao and Mark Gertler (1999), "Overreaction of Asset Prices in General Equilibrium," Review of Economic Dynamics.

Arellano, Cristina (2005), "Default Risk and Aggregate Fluctuations in Emerging Economies," mimeo, University of Minnesota.

Auenhaimer, Leonardo and Roberto Garcia-Saltos (2000), "International Debt and the Price of Domestic Assets, " IMF Working Paper 00/177.

Bernanke, Ben, Mark Gertler, and Simon Gilchrist (1999), "The Financial Accelerator in a Quantitative Business Cycle Framework," in J. Taylor and M. Woodford eds. Handbook of Macroeconomics, Volume 1C, ed. by, North-Holland.

Calvo, Guillermo A., (1998), "Capital Flows and Capital-Market Crises: The Simple Economics of Sudden Stops," Journal of Applied Economics, v.1, pp 35-54. , and Carmen M. Reinhart (1999), "When Capital Inflows come to a Sudden Stop: Consequences and Policy Options," mimeo, University of Maryland. , Alejandro Izquierdo, and Rudy Loo-Kung (2006), "Relative Price Volatility under Sudden Stops: The Relevance of Balance-Sheet Effects," Journal of International Economics, v. 69, pp. 231-254.

, Alejandro Izquierdo, and Ernesto Talvi (2006), "Phoenix Miracles in Emerging Markets: Recovering without Credit from Systemic Financial Crises," Working Paper No. 570, Research Department, Inter-American Development Bank.

Choi, Woon Gyu and David Cook (2003), "Liability Dollarization and the Bank Balance Sheet Channel," Journal of International Economics.

Cooley, Thomas, Ramon Marimon and Vincenzo Quadrini (2004), "Aggregate Consequences of Limited Contract Enforceability," Journal of Pol. Economy, 111(4).

Cook, David and Devereux, Michael B., (2006a), "External Currency Pricing and the East Asian Crisis," Journal of International Economics, v. 69, pp. 37-63.

Cook, David and Devereux, Michael B., (2006b), "Accounting for the East Asian Crisis: A Quantitative Model of Capital Outflows in a Small Open Economies," Journal of Money, Credit and Banking, forthcoming.

Dunbar, Nicholas, (2000) Inventing Money: The Story of Long-Term Capital Management and the Legends Behind it, John Wiley \& Sons Ltd., West Sussex: England.

Durdu, C. Bora, Enrique G. Mendoza, and Marco Terrones, (2008), "Precautionary Demand for Foreign Assets in Sudden Stop Economies: An Assessment of the New Mercantilism," Journal of Development Economics, forthcoming.

Epstein Larry G. (1983), "Stationary Cardinal Utility and Optimal Growth under Uncertainty," Journal of Economic Theory, 31, 133-152.

Fisher, Irving (1933), "The Debt-Deflation Theory of Great Depressions," Econometrica 1, 337-57.

Gertler, Mark, Simon Gilchrist and Fabio M. Natalucci (2007), "External Constraints on Monetary Policy," Journal of Money, Credit and Banking, v. 39, No. 2-3, pp.295-330.

Garcia Cicco, Javier, Pancrazi, Roberto and Martin Uribe (2006), "Real Business Cycles in Emerging Countries?," NBER Working Paper No. W12629.

Garcia-Verdu, Rodrigo (2005), "Factor Shares from Household Survey Data," mimeo, Research Department, Banco de Mexico.

Goldberg, Linda S. and Jose Manuel Campa (2006), "Distribution Margins, Imported Inputs, and the Insensitivity of the CPI to Exchange Rates," mimeo, Research Department, Federal Reserve Bank of New York. 
Gopinath, Gita (2003), "Lending Booms, Sharp Reversals and Real Exchange Rate Dynamics," Journal of International Economics.

Greenwood, Jeremy, Zvi Hercowitz and Gregory W. Huffman (1988), "Investment, Capacity Utilization \& the Real Business Cycle", American Economic Review, June.

Izquierdo, Alejandro (2000) "Credit Constraints, and the Asymmetric Behavior of Asset Prices and Output under External Shocks," mimeo, The World Bank. June.

Jermann, Urban and Vincenzo Quadrini (2005), "Financial Innovations and Macroeconomic Volatility," mimeo, Wharton School of Business.

Hayashi, Fumio (1982), "Tobin's Marginal q and Average q: A Neoclassical Interpretation," Econometrica, v. 50, no. 1, 213-224.

International Monetary Fund (2002), World Economic Outlook, September.

Kiyotaki, Nobuhiro and John Moore (1997), "Credit Cycles," Journal of Political Economy, v.105, 211-248.

Kocherlakota, Narayana (2000) "Creating Business Cycles Through Credit Constraints," Federal Reserve Bank of Minneapolis Quarterly Review, v. 24, no. 3, Summer, 2-10.

Lane, Philip R. and Gian Maria Milesi-Ferretti, (2001), "The External Wealth of Nations: Measures of Foreign Assets and Liabilities for Industrial and Developing Countries," Journal of International Economics, 55, 263-294.

Martin, Phillippe and Helene Rey, (2006), "Globalization and Emerging Markets: With or Without Crash?," American Economic Review, forthcoming.

Mendoza, Enrique G. (2006), "Endogenous Sudden Stops in a Business Cycle Model with Collateral Constraints: A Fisherian Deflation of Tobin's Q." NBER WP No. 12564 , (2002), "Credit, Prices, and Crashes: Business Cycles with a Sudden Stop." In Preventing Currency Crises in Emerging Markets, Frankel, Jeffrey and Sebastian Edwards eds. Chicago: University of Chicago Press. , (1995), "The Terms of Trade, The Real Exchange Rate and Economic Fluctuations," International Economic Review, v. 36, 101-137, February. , (1991), "Real Business Cycles in a Small Open Economy," American Economic Review, v. 81, 797-818, September. , and Katherine A. Smith (2006), "Quantitative Implications of a Debt-Deflation Theory of Sudden Stops \& Asset Prices," Journal of Int. Econ. , and Vivian Z. Yue (2008), "A Solution to the Default Risk-Business Cycle Disconnect," NBER Working Paper no. 13861.

Milesi-Ferretti, Gian Maria, and Assaf Razin (2000), "Current Account Reversals and Currency Crises: Empirical Regularities." In Currency Crises, Paul Krugram ed. Chicago: University of Chicago Press.

Neumeyer, P. Andres and Fabrizio Perri (2005), "Business Cycles in Emerging Economies: The Role of Interest Rates," Journal of Monetary Economics, forthcoming.

Oviedo, P. Marcelo (2004), "Intermediation of Capital Inflows: The Macroeconomic Implications of Neoclassical Banks \&Working Capital," mimeo, Iowa State University.

Schmitt-Grohe, Stephanie and Martin Uribe (2002), "Closing Small Open Economy Models," Journal of International Economics.

Uribe, Martin and Zhanwei Vivian Yue, (2006), "Country Spreads and Emerging Countries: Who Drives Whom?," Journal of International Economics, v. 69, 6-36. 
Table 1: Calibrated Parameter Values

\begin{tabular}{|c|c|c|c|}
\hline \multicolumn{4}{|c|}{ Paramaters set with ratios from data and deterministic steady state conditions } \\
\hline$\alpha$ & 0.592 & labor share set to yield 0.66 share in GDP as & $\alpha /(1-\eta)$ \\
\hline$\beta$ & 0.306 & capital share set to yield 0.33 share in GDP as & $\beta /(1-\eta)$ \\
\hline$\delta$ & 0.088 & \multicolumn{2}{|l|}{ depreciation rate from perpetual inventories method } \\
\hline $\mathrm{R}$ & 1.0857 & \multicolumn{2}{|l|}{ implied by s.s.optimal investment rule } \\
\hline$w$ & 1.846 & \multicolumn{2}{|c|}{ regression estimate using labor supply optimality condition } \\
\hline$\gamma$ & 0.0166 & \multicolumn{2}{|l|}{ implied by s.s. consumption Euler eq. } \\
\hline$b / g d p$ & -0.86 & \multicolumn{2}{|l|}{ implied by s.s. budget constraint } \\
\hline \multicolumn{4}{|c|}{ Average ratios from Mexican data (1993-2005) } \\
\hline$\eta=p v / y$ & 0.102 & \multicolumn{2}{|l|}{ imported inputs/gross output ratio } \\
\hline$k / y$ & 1.758 & \multicolumn{2}{|l|}{ capital/gross output ratio } \\
\hline$p v / g d p$ & 0.114 & \multicolumn{2}{|l|}{ imported inputs/gdp ratio } \\
\hline$g d p / y$ & 0.896 & \multicolumn{2}{|l|}{ gdp/gross output ratio } \\
\hline$c / g d p$ & 0.65 & \multicolumn{2}{|l|}{ consumption/gdp ratio } \\
\hline$g / g d p$ & 0.110 & \multicolumn{2}{|l|}{ gov. purchases/gdp ratio } \\
\hline$i / g d p$ & 0.172 & \multicolumn{2}{|l|}{ investment/gdp ratio } \\
\hline$g / c$ & 0.168 & \multicolumn{2}{|l|}{ ratio of public to private consumption } \\
\hline \multicolumn{4}{|c|}{ Parameters set with SMM } \\
\hline$a$ & 2.75 & \multicolumn{2}{|c|}{ targeted to match ratio of s.d. of investment to s.d. of gdp } \\
\hline$\phi$ & 0.2579 & \multicolumn{2}{|c|}{ targeted to yield a mean working capital/gdp ratio of 0.2} \\
\hline
\end{tabular}


Table 2. Mexico: Business Cycle Statistics and the Sudden Stop of 1995

\begin{tabular}{|c|c|c|c|c|c|}
\hline variable & $\begin{array}{l}\text { standard } \\
\text { deviation }\end{array}$ & $\begin{array}{l}\text { standard dev. } \\
\text { relative to GDP }\end{array}$ & $\begin{array}{c}\text { correlation } \\
\text { with } \\
\text { GDP } \\
\end{array}$ & $\begin{array}{c}\text { first-order } \\
\text { autocorrelation }\end{array}$ & $\begin{array}{c}\text { Sudden Stop } \\
\text { (date in brackets) }\end{array}$ \\
\hline GDP & 2.723 & 1.000 & 1.000 & 0.749 & $\begin{array}{c}-8.315 \\
(1995: 2)\end{array}$ \\
\hline intermediate goods imports & 7.850 & 2.882 & 0.905 & 0.759 & $\begin{array}{l}-27.229 \\
(1995: 2)\end{array}$ \\
\hline $\begin{array}{l}\text { private consumption } \\
\text { total }\end{array}$ & 3.397 & 1.247 & 0.895 & 0.701 & $\begin{array}{c}-8.175 \\
(1995: 3)\end{array}$ \\
\hline non durables \& services & 2.490 & 0.914 & 0.893 & 0.676 & $\begin{array}{c}-5.649 \\
(1995: 2)\end{array}$ \\
\hline investment & 9.767 & 3.586 & 0.944 & 0.816 & $\begin{array}{l}-30.074 \\
(1995: 3)\end{array}$ \\
\hline net exports-GDP ratio & 2.109 & 0.775 & -0.688 & 0.797 & $\begin{array}{c}4.898 \\
(1995: 2)\end{array}$ \\
\hline current account-GDP ratio & 1.560 & 0.573 & -0.754 & 0.720 & $\begin{array}{c}3.838 \\
(1995: 2)\end{array}$ \\
\hline equity prices & 14.648 & 5.379 & 0.570 & 0.640 & $\begin{array}{l}-27.397 \\
(1995: 2)\end{array}$ \\
\hline intermediate goods prices & 3.345 & 1.228 & -0.377 & 0.737 & $\begin{array}{c}5.915 \\
(1995: 1)\end{array}$ \\
\hline world real interest rate & 1.958 & 0.719 & -0.590 & 0.572 & $\begin{array}{c}6.752 \\
(1995: 2)\end{array}$ \\
\hline total factor productivity & 1.340 & 0.492 & 0.519 & 0.537 & $\begin{array}{c}-5.082 \\
(1995: 2)\end{array}$ \\
\hline
\end{tabular}

Note: The data were expressed in per capita terms, logged and detrended with the Hodrick-Prescott filter. Equity prices are in units of the GDP deflator. Intermediate goods prices are defined as the ratio of the deflator of imported intermediated goods divided by the exports deflator. "Sudden Stop" corresponds to the lowest deviation from trend observed in the corresponding variable (for variables in GDP ratios it is the largest change in percentage points observed in two consecutive quarters).

The world real real interest rate is the sum of the return on 3-month U.S. T bills plus the EMBI+ spread for Mexican sovereign debt minus a measure of expected U.S. CPI inflation (see Uribe and Yue (2005) for details). Total factor productivity is measured using a production function for gross output that includes capital, labor and imported intermediate goods. The data are for the period 1993:1-2005:2, except the Uribe-Yue real interest rate, which is for the period 1994:1-2004:1. 
Table 3. Long-Run Business Cycle Moments

\begin{tabular}{|c|c|c|c|c|c|}
\hline variable & mean & $\begin{array}{c}\text { Standard } \\
\text { deviation } \\
\text { (in percent) }\end{array}$ & $\begin{array}{c}\text { Standard } \\
\text { deviation } \\
\text { relative to GDP }\end{array}$ & $\begin{array}{c}\text { correlation } \\
\text { with } \\
\text { GDP } \\
\end{array}$ & $\begin{array}{c}\text { first-order } \\
\text { autocorrelation }\end{array}$ \\
\hline \multicolumn{6}{|c|}{ I. Economy without Collateral Constraint } \\
\hline$g d p$ & 390.135 & $3.90 \%$ & 1.000 & 1.000 & 0.822 \\
\hline$c$ & 263.152 & $4.21 \%$ & 1.080 & 0.861 & 0.817 \\
\hline$i$ & 66.203 & $13.85 \%$ & 3.552 & 0.616 & 0.493 \\
\hline$n x / g d p$ & 0.042 & $3.00 \%$ & 0.769 & -0.191 & 0.549 \\
\hline$k$ & 752.270 & $4.39 \%$ & 1.125 & 0.756 & 0.962 \\
\hline$b / g d p$ & -0.326 & $17.57 \%$ & 4.505 & -0.023 & 0.175 \\
\hline$q$ & 1.000 & $3.33 \%$ & 0.854 & 0.379 & 0.440 \\
\hline leverage ratio & -0.266 & $8.32 \%$ & 2.133 & 0.001 & 0.083 \\
\hline$v$ & 42.247 & $5.85 \%$ & 1.501 & 0.830 & 0.776 \\
\hline \multirow[t]{4}{*}{ working capital } & 75.993 & $4.32 \%$ & 1.107 & 0.995 & 0.801 \\
\hline & \multicolumn{2}{|c|}{ Savings-investment correlation } & 0.539 & & \\
\hline & \multicolumn{2}{|c|}{ GDP-world interest rate correlation } & -0.665 & & \\
\hline & \multicolumn{2}{|c|}{ GDP-int. goods price correlation } & -0.168 & & \\
\hline \multicolumn{6}{|c|}{ II. Economy with $30 \%$ Collateral Coefficient $(\kappa=0.30)$} \\
\hline$g d p$ & 389.512 & $3.96 \%$ & 1.000 & 1.000 & 0.818 \\
\hline$c$ & 264.581 & $4.07 \%$ & 1.030 & 0.909 & 0.792 \\
\hline$i$ & 66.093 & $13.66 \%$ & 3.453 & 0.628 & 0.492 \\
\hline$n x / g d p$ & 0.036 & $2.76 \%$ & 0.697 & -0.213 & 0.490 \\
\hline$k$ & 751.015 & $4.39 \%$ & 1.109 & 0.751 & 0.963 \\
\hline$b / g d p$ & -0.257 & $12.57 \%$ & 3.177 & -0.071 & 0.124 \\
\hline$q$ & 1.000 & $3.28 \%$ & 0.828 & 0.390 & 0.438 \\
\hline leverage ratio & -0.232 & $5.86 \%$ & 1.482 & -0.043 & 0.058 \\
\hline$v$ & 42.128 & $6.02 \%$ & 1.523 & 0.836 & 0.770 \\
\hline \multirow[t]{4}{*}{ working capital } & 75.777 & $4.51 \%$ & 1.139 & 0.990 & 0.785 \\
\hline & \multicolumn{2}{|c|}{ Savings-investment correlation } & 0.512 & & \\
\hline & \multicolumn{2}{|c|}{ GDP-world interest rate correlation } & -0.657 & & \\
\hline & \multicolumn{2}{|c|}{ GDP-int. goods price correlation } & -0.173 & & \\
\hline \multicolumn{6}{|c|}{ III. Economy with $20 \%$ Collateral Coefficient $(\kappa=0.2)$} \\
\hline$g d p$ & 388.339 & $3.85 \%$ & 1.000 & 1.000 & 0.815 \\
\hline$c$ & 267.857 & $3.69 \%$ & 0.959 & 0.931 & 0.766 \\
\hline$i$ & 65.802 & $13.45 \%$ & 3.496 & 0.641 & 0.483 \\
\hline$n x / g d p$ & 0.024 & $2.58 \%$ & 0.671 & -0.184 & 0.447 \\
\hline$k$ & 747.709 & $4.31 \%$ & 1.120 & 0.744 & 0.963 \\
\hline$b / g d p$ & -0.104 & $8.90 \%$ & 2.313 & -0.298 & 0.087 \\
\hline$q$ & 1.000 & $3.23 \%$ & 0.839 & 0.406 & 0.428 \\
\hline leverage ratio & -0.159 & $4.07 \%$ & 1.057 & -0.258 & 0.040 \\
\hline$v$ & 41.949 & $5.84 \%$ & 1.517 & 0.823 & 0.764 \\
\hline \multirow[t]{4}{*}{ working capital } & 75.455 & $4.26 \%$ & 1.107 & 0.987 & 0.777 \\
\hline & \multicolumn{2}{|c|}{ Savings-investment correlation } & 0.391 & & \\
\hline & \multicolumn{2}{|c|}{$G D P$-world interest rate correlation } & -0.645 & & \\
\hline & \multicolumn{2}{|c|}{ GDP-int. goods price correlation } & -0.180 & & \\
\hline
\end{tabular}


Table 4. Amplification and Asymmetry Features of Sudden Stop Events (mean differences relative to frictionless economy in percent of frictionless averages)
(1)
(2)
(3)
(4)

(5)

baseline economy lower collateral coefficient higher collateral coefficient zero net exports

\begin{tabular}{|c|c|c|c|c|c|c|c|c|c|c|}
\hline & \multicolumn{2}{|c|}{$\kappa=0.20$} & \multicolumn{2}{|c|}{$\kappa=0.30$} & \multicolumn{2}{|c|}{$\kappa=0.15$} & \multicolumn{2}{|c|}{ threshold } & \multicolumn{2}{|c|}{ no working capital } \\
\hline & $\begin{array}{l}\text { S.S. } \\
\text { states }\end{array}$ & $\begin{array}{c}\text { non S.S. } \\
\text { states }\end{array}$ & $\begin{array}{c}\text { S.S. } \\
\text { states }\end{array}$ & $\begin{array}{c}\text { non S.S. } \\
\text { states }\end{array}$ & $\begin{array}{c}\text { S.S. } \\
\text { states }\end{array}$ & $\begin{array}{c}\text { non S.S. } \\
\text { states }\end{array}$ & $\begin{array}{c}\text { S.S } \\
\text { states }\end{array}$ & $\begin{array}{c}\text { non S.S } \\
\text { states }\end{array}$ & $\begin{array}{c}\text { S.S } \\
\text { states }\end{array}$ & $\begin{array}{c}\text { non S.S } \\
\text { states }\end{array}$ \\
\hline$g d p$ & -1.13 & -0.11 & -1.18 & -0.06 & -1.21 & -0.14 & -0.86 & -0.06 & 0.00 & 0.00 \\
\hline$c$ & -3.25 & -0.31 & -3.17 & -0.14 & -3.15 & -0.42 & -2.12 & -0.23 & -1.54 & -0.34 \\
\hline$i$ & -11.84 & -0.61 & -10.73 & -0.18 & -12.35 & -0.91 & -7.48 & -0.30 & -9.71 & -1.25 \\
\hline$q$ & -2.88 & -0.15 & -2.64 & -0.04 & -2.99 & -0.22 & -1.81 & -0.07 & -2.53 & -0.31 \\
\hline$n x / g d p$ & 3.56 & 0.25 & 3.32 & 0.08 & 3.47 & 0.34 & 2.13 & 0.17 & 3.11 & 0.49 \\
\hline$b / g d p$ & 3.57 & 0.25 & 3.00 & 0.06 & 3.60 & 0.36 & 2.11 & 0.18 & 3.31 & 0.53 \\
\hline lev. ratio & 1.31 & 0.12 & 0.89 & 0.04 & 1.47 & 0.18 & 0.83 & 0.09 & 0.90 & 0.17 \\
\hline$L$ & -1.71 & -0.16 & -1.79 & -0.09 & -1.83 & -0.22 & -1.29 & -0.10 & 0.00 & 0.00 \\
\hline$v$ & -3.10 & -0.29 & -3.21 & -0.16 & -3.31 & -0.40 & -2.36 & -0.18 & 0.00 & 0.00 \\
\hline w. cap. & -3.12 & -0.29 & -3.25 & -0.16 & -3.34 & -0.40 & -2.37 & -0.18 & na & na \\
\hline$R$ & 0.00 & 0.00 & 0.00 & 0.00 & 0.00 & 0.00 & 0.00 & 0.00 & 0.00 & 0.00 \\
\hline$p$ & 0.00 & 0.00 & 0.00 & 0.00 & 0.00 & 0.00 & 0.00 & 0.00 & 0.00 & 0.00 \\
\hline$t f p$ & 0.00 & 0.00 & 0.00 & 0.00 & 0.00 & 0.00 & 0.00 & 0.00 & 0.00 & 0.00 \\
\hline prob. of SS events & \multicolumn{2}{|c|}{$3.32 \%$} & \multicolumn{2}{|c|}{$1.07 \%$} & \multicolumn{2}{|c|}{$3.92 \%$} & \multicolumn{2}{|c|}{$9.54 \%$} & \multicolumn{2}{|c|}{$0.07 \%$} \\
\hline$b / g d p$ in $S S$ events & \multicolumn{2}{|c|}{-0.21} & \multicolumn{2}{|c|}{-0.44} & \multicolumn{2}{|c|}{-0.17} & \multicolumn{2}{|c|}{-0.20} & \multicolumn{2}{|c|}{-0.40} \\
\hline
\end{tabular}

Note: Sudden Stop states are defined as states in which the collateral constraint binds with positive long-run probability and the net exports-GDP ratio is at least 2 percentage points above its mean. 
Figure 1: Macroeconomic Dynamics around Sudden Stop Events in Emerging Economies (cross-country medians of deviations from HP trends)
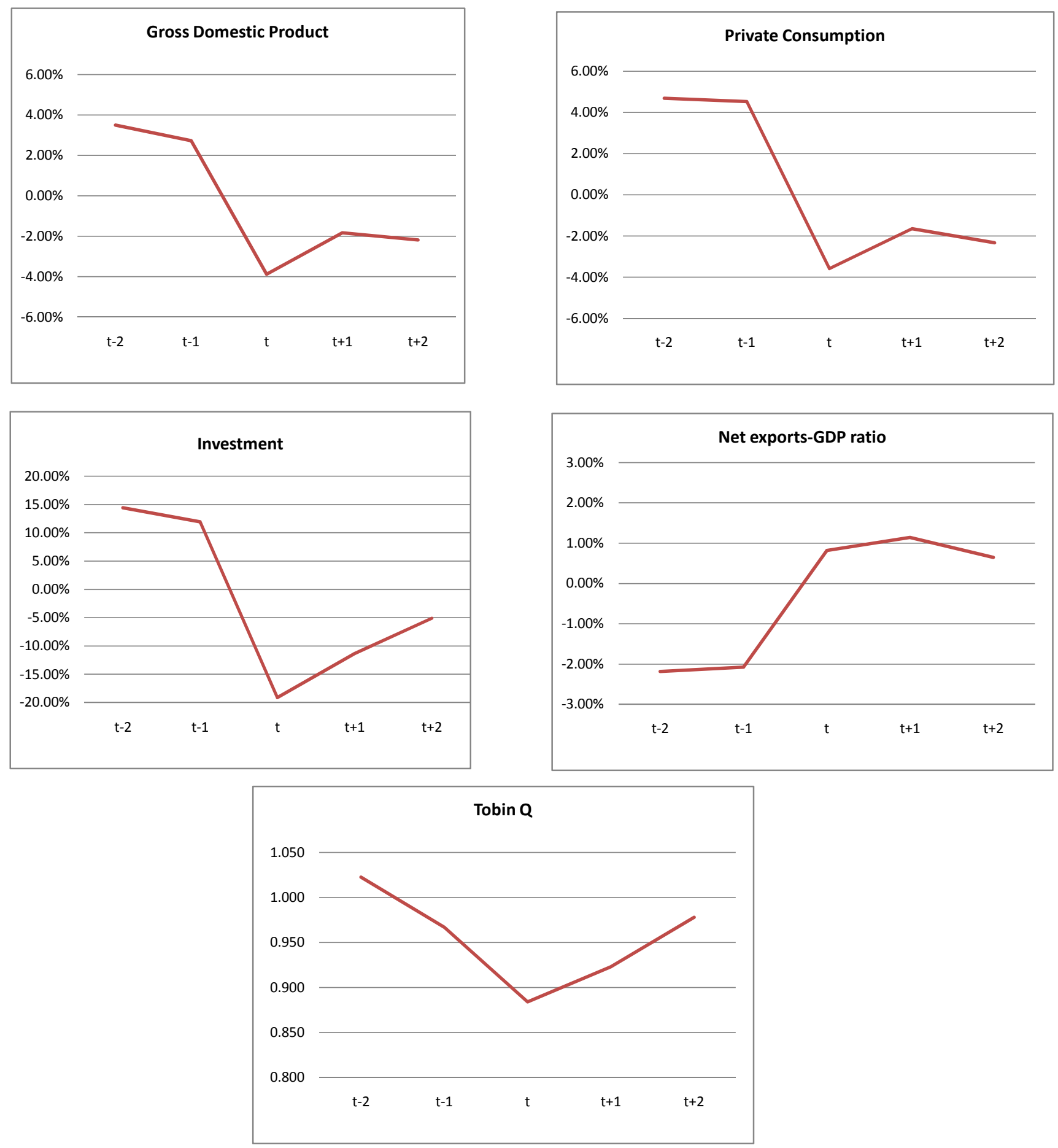

Note: The classification of Sudden Stop events in the emerging markets data is taken from Calvo et al. (2006). They define systemic sudden stop events as episodes with mild and large output collapses that coincide with large spikes in the EMBI spread and large reversals in capital flows. Tobin' $Q$ is the ratio of debt outstanding over book value of equity, and it is shown in levels instead of deviation from HP trend. 
Figure 2 : Sudden Stop Event Windows in Actual Data and Model Simulations (medians of deviations from HP trends)
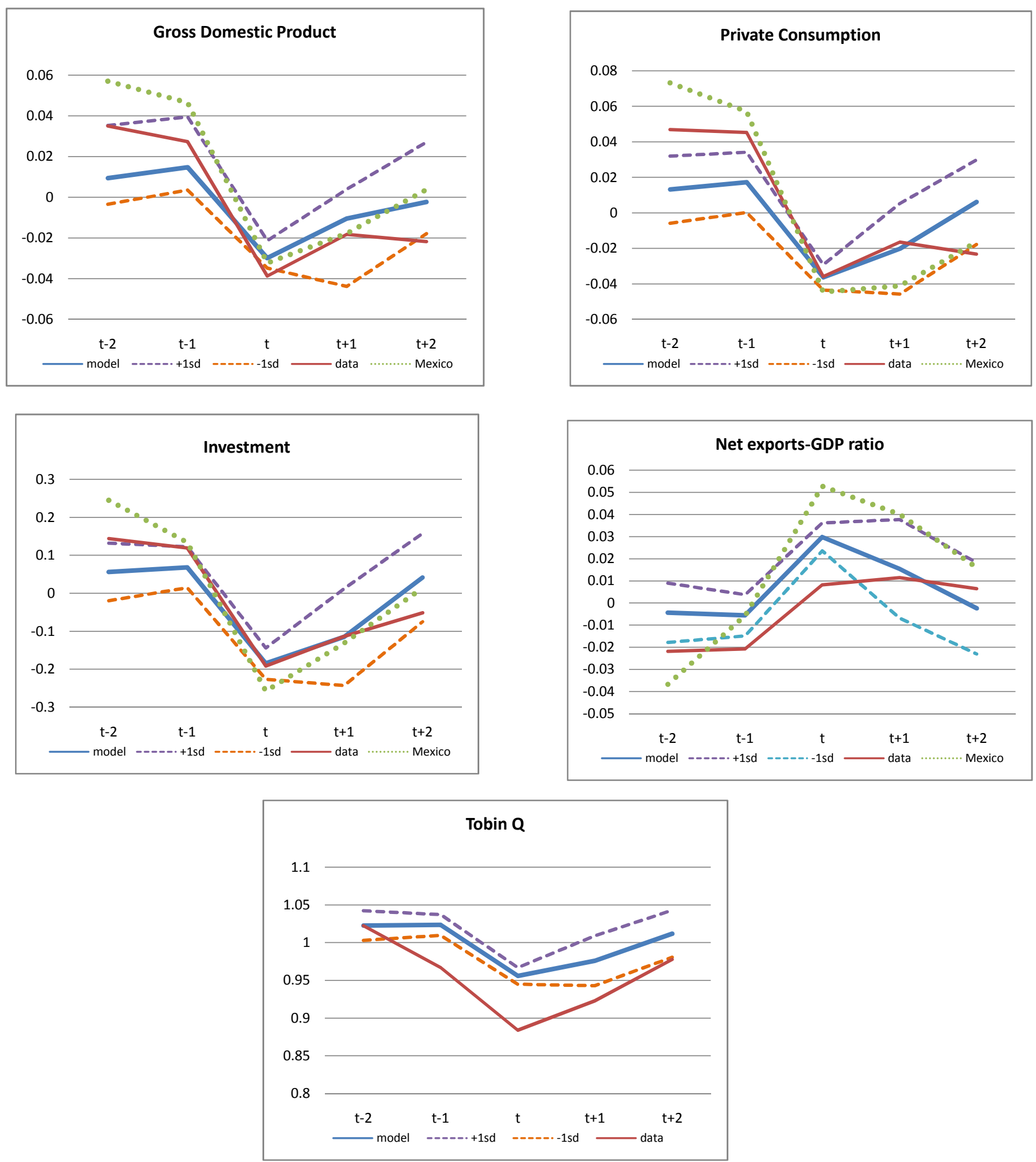

Note: Events from actual data are as in Figure 1, which uses the definitions from Calvo et al. (2006). Mexican data are for the Sudden Stop of 1995. Sudden Stop events in the model simulations are defined in a manner analogous to Calvo et al, as events in which the collateral constraint binds, output is at least one-standard-deviation below trend, and the trade balance-GDP ratio is at least one-standard-deviation above trend. Tobin's $Q$ is shown in levels. 
Figure 3: Solow Residuals and "True" TFP in Sudden Stop Events (means of deviations from long-run averages)
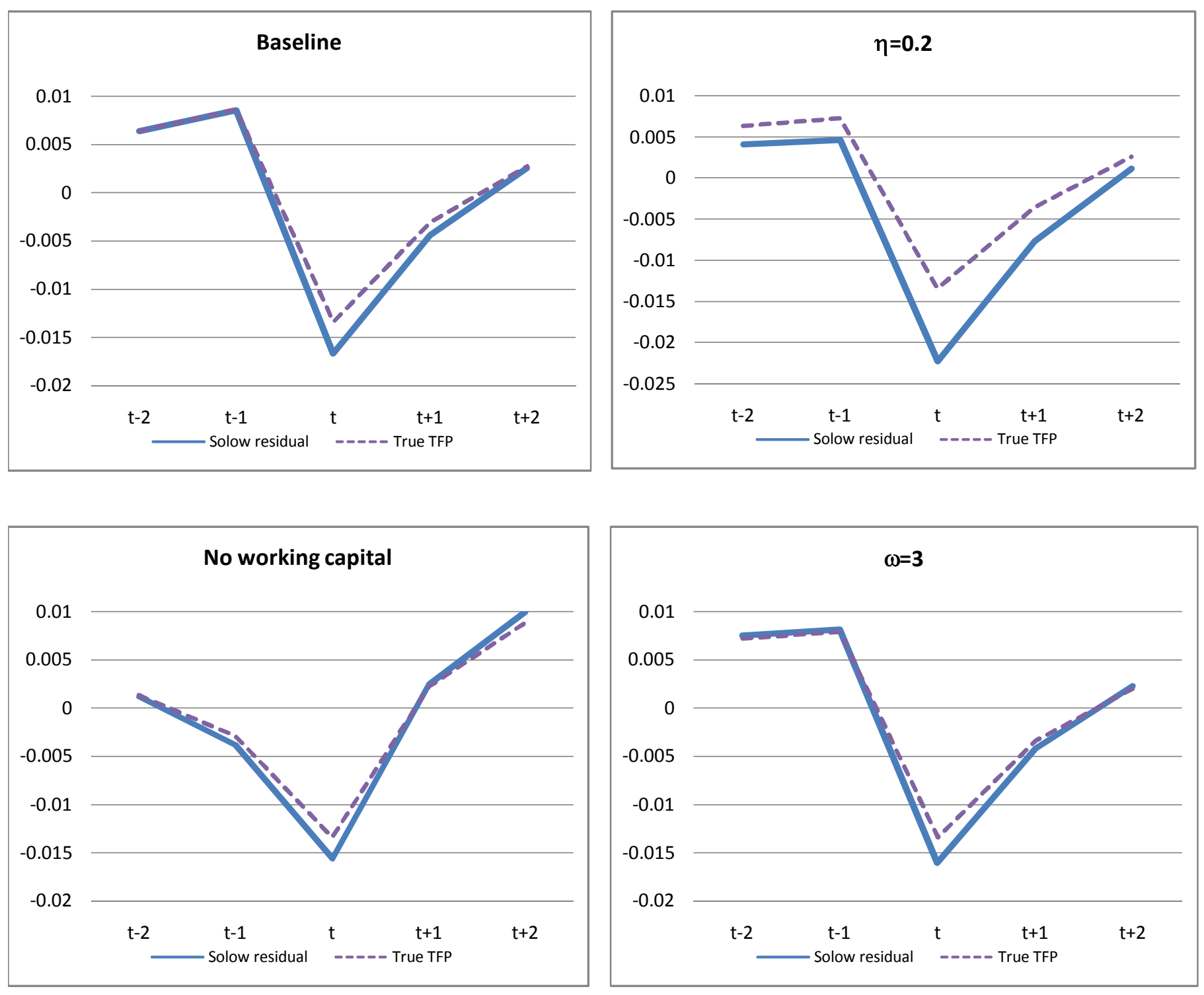
Figure 4: Sensitivity Analysis of Sudden Stop Events (medians of deviations from HP trends)
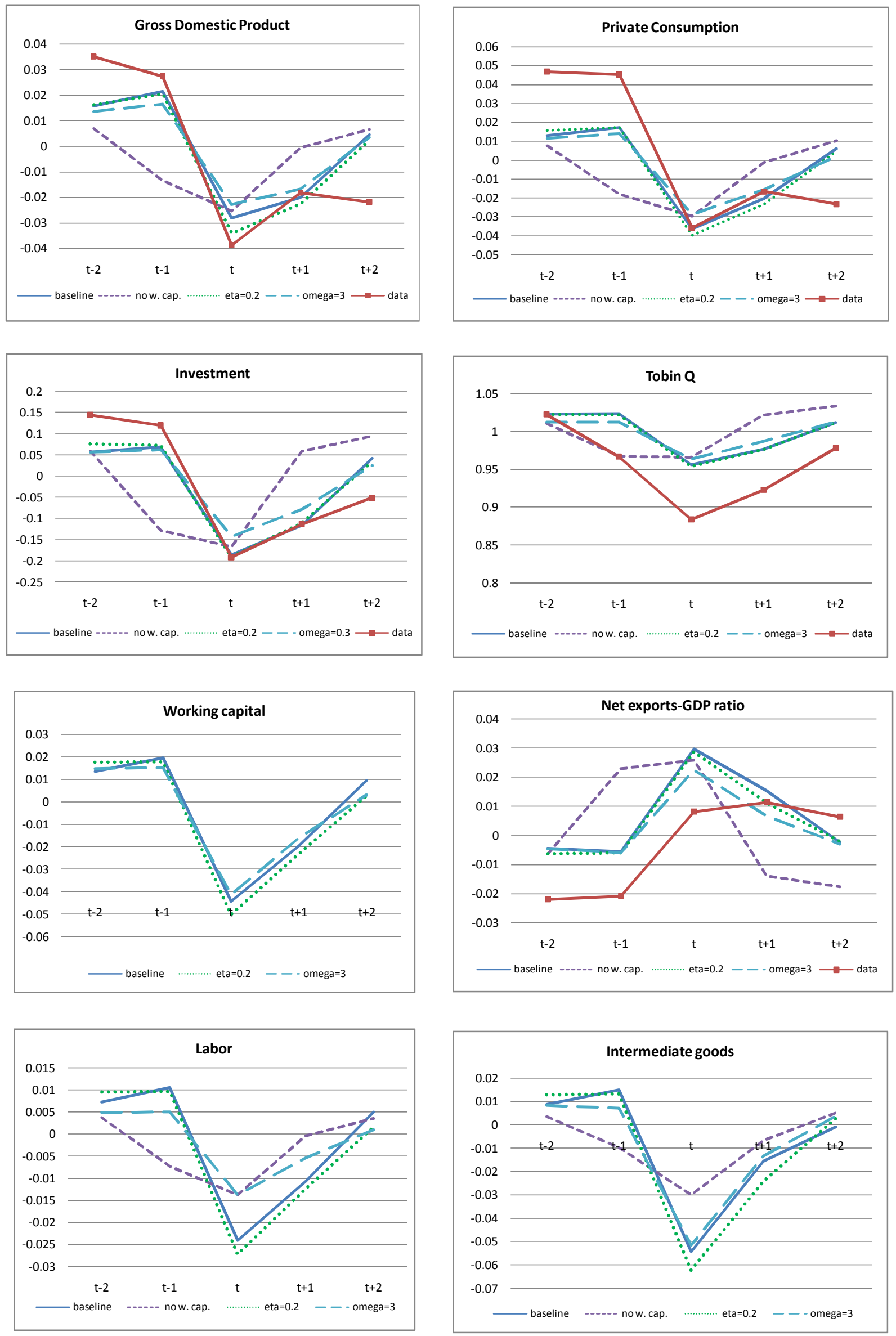